\title{
The subiculum: Unique hippocampal hub and more
}

Nobuyoshi Matsumoto, Takuma Kitanishi, Kenji Mizuseki

\begin{tabular}{|c|l|}
\hline Citation & Neuroscience Research. 143; 1-12 \\
\hline Published & $2019-07$ \\
\hline Type & Journal Article \\
\hline Textversion & Publisher \\
\hline \multirow{3}{*}{ Rights } & $\begin{array}{l}\text { C } 2018 \text { Elsevier B.V. and Japan Neuroscience Society. This manuscript version is } \\
\text { made available under the CC-BY-NC-ND 4.0 License. } \\
\text { https://creativecommons.org/licenses/by-nc-nd/4.0/ } \\
\text { This is the accepted manuscript version. The article has been published in final } \\
\text { form at https://doi.org/10.1016/j.neures.2018.08.002. }\end{array}$ \\
\hline DOI & \begin{tabular}{l} 
10.1016/j.neures.2018.08.002 \\
\hline
\end{tabular} \\
\hline
\end{tabular}

\author{
Self-Archiving by Author(s) \\ Placed on: Osaka City University
}




\title{
The subiculum: unique hippocampal hub and more
}

\author{
Running head: Uniqueness of subiculum \\ Nobuyoshi Matsumoto $^{\mathrm{a}, \mathrm{b}}$, Takuma Kitanishi ${ }^{\mathrm{a}, \mathrm{b}, \dagger}$, Kenji Mizuseki $^{\mathrm{a}, \mathrm{b}}$ \\ ${ }^{a}$ Department of Physiology, Osaka City University Graduate School of Medicine, \\ Osaka 545-8585, Japan \\ ${ }^{\mathrm{b}}$ Center for Brain Science, Osaka City University Graduate School of Medicine, \\ Osaka 545-8585, Japan
}

Key words: subiculum, oscillations, place cells, membrane potentials

$†$ To whom correspondence should be addressed:

Takuma Kitanishi, $\mathrm{PhD}$

Department of Physiology

Osaka City University Graduate School of Medicine, 1-4-3 Asahimachi, Abeno-ku, Osaka, 545-8585, Japan

Tel: +81-6-6645-3717

E-mail: kitanishi.takuma@med.osaka-cu.ac.jp

\section{Acknowledgments:}

This work is supported by JSPS KAKENHI (18H05137, 17K19462, 16H04656, 16H01279, (K.M.), 17H05575, 17H05977, 17K14939 (T.K.), $17 J 10860$ (N.M.)), Daiichi Sankyo Foundation of Life Science (K.M.), the Naito Foundation (K.M.), Mochida Memorial Foundation for Medical and Pharmaceutical Research (K.M.), Astellas Foundation for Research on Metabolic Disorders (K.M.), SEI Group CSR Foundation (K.M. and T.K.), the Asahi Glass Foundation (K.M.), Hokuto Foundation for Bioscience (K.M.), Toray Science Foundation (K.M.), Life Science Foundation of Japan (K.M. and T.K.), Shimadzu Science Foundation (K.M.), the Tokyo Biochemical Research Foundation (K.M.), Brain Science Foundation (K.M.), the Ichiro Kanehara Foundation for the Promotion of Medical Science \& Medical Care (K.M.), the Uehara Memorial Foundation (K.M.), the NOVARTIS Foundation (Japan) for the Promotion of Science (K.M.), Futaba Electronics Memorial Foundation (K.M.), the Osaka City University (OCU) Strategic Research Grant 2017 for basic researches (K.M.), the Japan Prize Foundation (T.K.), the Sumitomo Foundation (T.K.), Takeda Science Foundation (T.K.), Narishige Neuroscience Research 
Foundation (T.K.), the Nakajima Foundation (T.K.), and the Osaka City University (OCU) Strategic Research Grant 2017 for young researches (T.K.).

The authors declare that there are no competing financial interests. 


\begin{abstract}
The hippocampal formation, which comprises the hippocampus proper, dentate gyrus, and subiculum, is crucial for learning, memory, and spatial navigation. Historically, most studies have focused on the hippocampus proper and dentate gyrus; however, recent evidence has highlighted the substantial contribution of the subiculum to interregional communication and behavioral performance. Moreover, various network oscillations in the subiculum appear to be crucial for cognitive functions. The subiculum shows complicated spatial representation during exploratory behavior, suggesting that the subiculum does not simply relay hippocampal information to the target regions but it functions as a unique computational unit. The network mechanism underlying the uniqueness of the subiculum awaits further investigation.
\end{abstract}




\section{Introduction}

The hippocampal formation, which is generally defined as the region comprising the dentate gyrus, hippocampus proper (hereafter, the hippocampus), and the subiculum (van Strien et al., 2009) (Fig. 1A-1B), is crucial for episodic and spatial memory. The dentate gyrus and hippocampus process information consisting of mnemonic components by incorporating entorhinal inputs and then distributing the information to various brain areas (Buzsáki, 1996; Hunsaker and Kesner, 2018). Nevertheless, the mechanisms through which such multimodal hippocampal information is transferred to downstream brain areas remain elusive. The subiculum receives direct synaptic inputs from the hippocampal CA1 area and projects to various cortical and subcortical areas (see Section 2.3). This widespread projection pattern implies that the subiculum plays a crucial role in organizing hippocampal output (McNaughton, 2006). Moreover, the many features that distinguish the subiculum from the CA1 area, including its laminar structure (Section 2.1), cellular composition (Section 2.2), synaptic plasticity (Section 3), behavioral roles (Section 4), neural oscillations (Section 5.1), and spatial/non-spatial representations (Section 5.2), suggest that the subiculum has a unique function in information processing. Despite the postulated importance of the subiculum, considerably fewer studies have investigated subicular function compared with hippocampal function. Here we review the latest studies of this poorly-understood brain area to shed light on its fundamental function.

\section{Anatomy: cellular and circuit infrastructure of the subiculum}

\subsection{Structure}

The subiculum has a three-layered appearance comprising a molecular layer, a pyramidal cell layer, and a polymorphic layer (O’Mara, 2005; O’Mara et al., 2001) (Fig. 1C). The molecular layer is the most superficial (closest to the hippocampal fissure) layer and is continuous with the stratum radiatum and the stratum lacunosum-moleculare of 
the adjacent hippocampal CA1 area. The subicular pyramidal cell layer, which is flanked by the molecular and the polymorphic layers, is thicker than the hippocampal pyramidal cell layer. As its name suggests, this layer consists largely of pyramidal cells but with looser cell packing than in the stratum pyramidale of the hippocampus. The polymorphic layer is located deeper (i.e., closer to the alveus) than the pyramidal cell layer and is continuous with the stratum oriens of the CA1 area. Recent immunohistochemical investigation further characterized the internal structure of the subiculum (Ishihara and Fukuda, 2016), dividing it into proximal (closer to CA1 area) and distal (further from CA1 area) subfields based on differential cytoarchitecture and immunoreactivity for calbindin (Fujise et al., 1995). The proximal subiculum can be further subdivided into five layers along the superficial-deep axis based on expression of proteins, including neuron-specific nitric oxide synthase (nNOS) and Purkinje cell protein 4 (Ishihara and Fukuda, 2016). The subiculum exhibits a unique gene expression pattern in embryonic (Sheppard et al., 1995) and postnatal animals (Cembrowski et al., 2018; Lein et al., 2004; Roy et al., 2017), but to date, there is no widely-accepted molecular marker that identifies the whole subiculum.

\subsection{Cell types and morphology}

The principal cell type in the subiculum is pyramidal cells. Using single-cell labeling, Harris et al. (2001) revealed the dendritic and axonal morphology of subicular pyramidal cells. Most subicular pyramidal cells have a single primary apical dendrite with its first major branch point at the superficial edge of the pyramidal cell layer. The branches of the apical dendrites climb through the molecular layer, with many reaching the hippocampal fissure. Regardless of soma location, the basal dendritic arbors are similar across subicular pyramidal cells in their total arbor size and number of branches. Further, both apical and basal dendrites have numerous dendritic spines. 
Subicular pyramidal cells have axon collaterals that reach the alveus. Most also have axonal collaterals that climb into the apical dendritic region through the pyramidal cell layer. These collaterals have multiple varicosities both in the pyramidal cell layer and the apical dendritic region, suggesting that subicular pyramidal cells make synaptic contacts within the subiculum (Harris et al., 2001). Indeed, multiple whole-cell recordings have demonstrated extensive recurrent connections within the subiculum (Böhm et al., 2015). The axon collaterals extending obliquely across the cell layer toward the CA1 area or presubiculum are thought to project outside of the subiculum (Harris et al., 2001).

Subicular pyramidal cells are classified into at least two types based on their firing responses to intracellularly injected depolarizing current: the neurons that fire multiple action potentials within approximately $20 \mathrm{~ms}$ of pulse onset (Staff et al., 2000) are called intrinsically bursting neurons (mostly located in the deep cell layer), whereas neurons that discharge a single spike or train of action potentials with spike frequency adaptation are called regular-spiking neurons (mostly located in the superficial layer) in rodents (Behr et al., 1996; Harris et al., 2001; Harris and Stewart, 2001a; Knopp et al., 2005; Mattia et al., 1997; Menendez de la Prida, 2006; Menendez de la Prida et al., 2003; Staff et al., 2000; Stewart and Wong, 1993; Taube, 1993; Wellmer et al., 2002) (Fig. 1C) and humans (Wozny et al., 2005). The proportion of intrinsically bursting neurons is higher in the distal subiculum than in the proximal subiculum (Cembrowski et al., 2018; Jarsky et al., 2008) (Fig. 1C). There is recurrent connection both among regular-spiking neurons and intrinsically bursting neurons (connection probability: 4.7\%, regular-spiking to regular-spiking neurons; 3.7\%, bursting to bursting neurons). Regular-spiking neurons also innervate bursting neurons, but not vice versa (connection probability: 7.3\%, regularspiking to bursting neurons; 0\%, bursting to regular-spiking neurons) (Böhm et al., 2015) (Fig. 1C). When sinusoidal currents with constant amplitudes are applied to subicular 
neurons, both regular-spiking and intrinsically bursting neurons exhibit theta-frequency membrane resonance (Wang et al., 2006), similar to CA1 pyramidal cells (Zemankovics et al., 2010) and medial entorhinal stellate cells (Giocomo et al., 2007). These two neuron types differ in their dendritic morphology, projection targets, expressed receptors, and pharmacological responsiveness (Graves et al., 2012; Kim and Spruston, 2012).

In vitro intracellular recordings have provided detailed characterizations of subicular intrinsically bursting and regular-spiking neurons. The bursting neurons accompany fast after-hyperpolarization following serial spikes, which is related to the lack of accommodation and enable the neurons to incessantly discharge. On the other hand, both fast and $\mathrm{Ca}^{2+}$-dependent slow after-hyperpolarization follow a series of action potentials in regular-spiking neurons, which might allow for accommodation of a series of spikes (Behr et al., 1996). The bursting neurons receive greater tonic inhibition than regular-spiking neurons, suggesting that GABAergic inhibition may shape subicular output patterns (Panuccio et al., 2012). Another study demonstrated serotonin-induced reduction in the number of spikes in the burst and an increase in membrane conductance in subicular bursting neurons (Behr et al., 1997). Both calcium and sodium conductance are involved in the bursting firing of subicular pyramidal cells (Cooper et al., 2005; Jung et al., 2001; Mattia et al., 1997; Menendez de la Prida, 2006; Stewart and Wong, 1993; Taube, 1993; Wellmer et al., 2002). Using depolarizing current pulses, intrinsically bursting neurons can be further classified as "strong bursting" or "weak bursting" according to whether they repetitively burst or exhibit a single burst followed by regularspiking action potentials (Menendez de la Prida, 2006). Regular-spiking neurons can be further classified as "tonic" or "adaptive" based on the degree of spike frequency adaptation (Menendez de la Prida, 2006). The impact of activity of intrinsically bursting neurons on postsynaptic neurons is dependent on their firing patterns, as bursting neurons 
may depolarize postsynaptic neurons via facilitating or depressing synapses. By contrast, the impact of activity of regular-spiking neurons on postsynaptic neurons is relatively constant because they do not show prominent bursting activity. Therefore, intrinsically bursting neurons and regular-spiking neurons may have distinct roles in information transfer depending on the properties of the synapses made between these neurons and postsynaptic neurons. It remains to be explored what kind of information is transferred from what type of subicular neurons to what downstream neurons/regions via what type of synapses.

Interneurons are also present in the subiculum. Relative to the divergent types of interneurons that have been characterized in the hippocampus and neocortex based on their electrophysiological properties, morphology, and $\mathrm{Ca}^{2+}$-binding proteins, subicular interneurons are poorly characterized (Greene and Totterdell, 1997; Kawaguchi and Hama, 1987a; Knopp et al., 2008; Köhler et al., 1985; Seress et al., 1993; Soriano et al., 1993; Wang et al., 2017). Approximately $60 \%$ of putative GABAergic interneurons in the subiculum exhibit a fast-spiking firing pattern (Böhm et al., 2015). Fast-spiking, nonpyramidal cells are present in the pyramidal cell layer (Greene and Totterdell, 1997; Kawaguchi and Hama, 1987b; Menendez de la Prida et al., 2003), whereas chandelier cells are present in the molecular layer (Soriano et al., 1993). Based on $\mathrm{Ca}^{2+}$-binding proteins, parvalbumin-positive cells are mainly located in the pyramidal cell layer, whereas the majority of calretinin-positive cells are in the pyramidal cell layer and the molecular layer (Knopp et al., 2008). Some somatostatin-positive interneurons in the polymorphic layer express nicotinic acetylcholine receptor alpha2 subunits (Chrna2), which are reminiscent of oriens lacunosum-moleculare interneurons in the dorsal CA1 area (Leão et al., 2012; Nichol et al., 2018). Another cell type, called membrane potential oscillation cells, fires action potentials interspersed with membrane potential oscillations 
in reaction to depolarizing current pulses (Menendez de la Prida et al., 2003). Most of the membrane potential oscillation cells are morphologically indistinguishable from pyramidal cells (Menendez de la Prida et al., 2003).

\subsection{Projections}

\section{Afferents}

The subiculum is primarily innervated by the CA1 area and entorhinal cortex (Amaral et al., 1991; O'Mara, 2005; Witter, 2006) (Fig. 1D). The projection from the CA1 to the subiculum within the transverse plane shows similar topographical organization as the CA3-to-CA1 projection. Neurons in the distal (i.e., far from the dentate gyrus along the pyramidal cell layer) CA1 area have strong connections with neurons in the proximal (i.e., close to the dentate gyrus) subiculum, whereas neurons in the proximal CA1 area project to the distal subiculum neighboring the presubiculum (Amaral et al., 1991; O'Mara, 2005; Witter, 2006). This precise topographic projection from the proximal CA1 area to the distal subiculum requires teneurin-3 (Berns et al., 2018). The axons of CA1 neurons have been shown to terminate in the subicular pyramidal cell layer and a deep portion of the subicular molecular layer (Amaral et al., 1991). The subiculum also receives major inputs arising from layer III of the medial and lateral entorhinal cortices (Honda et al., 2012). The projection from the entorhinal cortex to the hippocampal formation is segregated: Layer III entorhinal neurons project to the CA1 area and the subiculum, whereas layer II stellate cells project to the dentate gyrus, CA3, and CA2 areas (Behr et al., 1998; Honda et al., 2012; Steward and Scoville, 1976; Tamamaki and Nojyo, 1993; Witter, 1993; Wyss, 1981). Layer II pyramidal cells in the medial entorhinal cortex, which are called island cells, densely project to the CA1 area and modestly project to the subiculum (Kitamura et al., 2014). Afferent subicular excitation by the CA1 area and medial entorhinal cortex exhibit cholinergic modulation (Kunitake et al., 2004). 
The ventral and medial parts of the anterior thalamic nuclei (i.e., the anteroventral and anteromedial thalamic nuclei), but not the dorsal part (i.e., the anterodorsal thalamic nucleus), might project to the temporal subiculum (Shibata, 1993; but see Jankowski et al., 2013; Mathiasen et al., 2017), suggesting that the subiculum receives theta-modulated head-direction signals in the anteroventral thalamic nucleus (Clark and Taube, 2012; Jankowski et al., 2013; Tsanov et al., 2011). Moreover, the subiculum is innervated by the basal amygdala (Cembrowski et al., 2018) and the nucleus reuniens of the thalamus (Wouterlood et al., 1990).

\section{Efferents}

The dorsal subiculum has been shown to have substantial efferent projections to various cortical and subcortical areas (Fig. 1D). The efferent projection arising from the rat dorsal subiculum reaches several cortical areas, including the retrosplenial cortex, medial prefrontal cortex, entorhinal cortex, perirhinal cortex, and postrhinal cortex (Aggleton and Christiansen, 2015; Honda and Ishizuka, 2015; Kinnavane et al., 2018; Kloosterman et al., 2003; Swanson and Cowan, 1977; Tamamaki and Nojyo, 1995; Witter, 2006; Witter et al., 1990). Moreover, neurons in the rodent dorsal subiculum innervate subcortical regions such as the hypothalamic nuclei (Kishi et al., 2000), nucleus accumbens (Groenewegen et al., 1987), midline thalamic nuclei (Namura et al., 1994), and lateral septum (Namura et al., 1994). Dorsal subicular neurons also project to the anteromedial and anteroventral thalamic nuclei and the mammillary bodies predominantly via the fornix in rodents (Bubb et al., 2017; Christiansen et al., 2016; Dillingham et al., 2015; Ishizuka, 2001; Kinnavane et al., 2018; Namura et al., 1994; Witter et al., 1990; Wright et al., 2010).

Accumulating evidence indicates that the subiculum also sends backward 
projections to the CA1 area (Berger et al., 1980; Harris and Stewart, 2001b; Köhler, 1985; Seress et al., 2002; Shao and Dudek, 2007; Sun et al., 2014; Xu et al., 2016). In line with this finding, some nNOS-immunoreactive pyramidal neurons in the subiculum innervate the CA1 area (Seress et al., 2002). Moreover, the dorsal subiculum innervates adult-born granule cells in the dentate gyrus (Deshpande et al., 2013), suggesting a potential impact on newborn granule cells involved in memory and emotion (Aimone et al., 2011; Nakashiba et al., 2012; Sahay et al., 2011a, 2011b; Santarelli et al., 2003).

The efferent projections from the subiculum are topographically organized along the proximodistal and dorsoventral axes. Individual subicular pyramidal cells exhibit a lower degree of axonal collateralization than CA1 pyramidal cells and project to only one or a few target brain areas (Naber and Witter, 1998). For instance, the dorsal-distal subiculum preferentially projects to the retrosplenial cortex, dorsal presubiculum, and medial entorhinal cortex, whereas the dorsal-proximal subiculum targets the nucleus accumbens, perirhinal cortex, prelimbic cortex, and lateral entorhinal cortex (Naber and Witter, 1998). The topographic projection from the subiculum to the parahippocampal areas becomes adult-like by postnatal day seven in rats (O'Reilly et al., 2013). Such a projection pattern that is widespread as a whole subiculum, but target-specific as individual projection neurons, implies that the subiculum plays a role in distributing distinct types of information to specific downstream target areas.

The subiculum adjoins the presubiculum (van Strien et al., 2009), which has a six-layered appearance (Honda et al., 2011, 2008; Honda and Ishizuka, 2004; Peng et al., 2017; Simonnet et al., 2013). The dorsal part of the presubiculum is often called the postsubiculum in rodents (Ding, 2013; Taube, 2007). While the subiculum has many unidirectional efferents, connections between the presubiculum/postsubiculum and their target regions are mostly reciprocal (Ding, 2013). For instance, the rat postsubiculum has 
reciprocal connections with the primary and secondary visual cortex (Vogt and Miller, 1983). Therefore, visual information of external landmarks may be transferred to the postsubiculum via the visual cortex, calibrating postsubicular head-direction signals (Knierim and Zhang, 2012; Yoder et al., 2011).

\section{Synaptic plasticity}

Synaptic plasticity, the activity-dependent plastic modification of synaptic transmission, is an important cellular learning process. The well-known forms of synaptic plasticity are the long-lasting increase (Bliss and Lømo, 1973) and decrease (Dudek and Bear, 1992; Mulkey and Malenka, 1992) in synaptic weights, which are called long-term potentiation (LTP) and long-term depression (LTD), respectively. CA1-to-subiculum synapses are known to exhibit both types of synaptic plasticity (Behr et al., 2009; O’Mara et al., 2000). Neurotransmission between CA1 and subicular pyramidal cells is mediated via presynaptic glutamate and postsynaptic AMPA-type and NMDA-type glutamate receptors (Behr et al., 1998). LTP is induced by high-frequency stimulation of the CA1to-subiculum pathway both in vitro (Boeijinga and Boddeke, 1996) and in vivo (Commins et al., 1998). At synapses from CA1 neurons onto regular-spiking subicular neurons, LTP is induced by a postsynaptic mechanism based on postsynaptic NMDA-receptor activation. By contrast, at synapses from CA1 neurons onto bursting subicular neurons, LTP is suggested to necessitate presynaptic NMDA-receptor activation and subsequent presynaptic $\mathrm{Ca}^{2+}{ }^{2+}$ influx (Behr et al., 2009).

Low-frequency stimulation that induces LTD at CA3-to-CA1 synapses or has little effect on these synapses rather result in moderate, late-developing LTP at CA1-tosubiculum synapses (Anderson et al., 2000; Huang and Kandel, 2005). This form of LTP is facilitated by $\beta$-adrenergic receptors in vitro (Huang and Kandel, 2005) and can be 
inhibited by acute stress in vivo (Macdougall and Howland, 2013). While these studies monitored population responses measured as field excitatory postsynaptic potentials, whole-cell recordings from single neurons have successfully induced CA1-subiculum LTD, which relies on postsynaptic muscarinic acetylcholine receptors and intracellular $\mathrm{Ca}^{2+}$ (Li et al., 2005). Bursting and regular-spiking neurons show distinct forms of synaptic plasticity in response to low-frequency stimuli at CA1-subiculum synapses. Low-frequency stimuli induce NMDA-receptor-dependent LTD in bursting cells and metabotropic glutamate receptor-dependent late-onset LTP in regular-spiking cells, both of which require postsynaptic $\mathrm{Ca}^{2+}$-signaling (Fidzinski et al., 2008). The polarity of this bidirectional synaptic plasticity in subicular neurons is modulated by muscarinic acetylcholine receptors and voltage-gated L-type $\mathrm{Ca}^{2+}$ channels (Shor et al., 2009).

Cell-type specificity is an intriguing feature of subicular synaptic plasticity. As described above, bursting neurons and regular-spiking neurons have distinct molecular mechanisms for inducing synaptic plasticity and may show opposite polarity (i.e., either LTP or LTD) in response to the same stimulation frequency. Such properties indicate that a single input pattern from upstream areas can regulate the synaptic strength of bursting and regular-spiking neurons in different ways. Because these two types of principal neurons preferentially project to different sets of target areas (Kim and Spruston, 2012), this simultaneously-occurring, distinct synaptic plasticity may flexibly change the output balance of the subiculum from one set of projection targets to another set of targets. Moreover, the involvement of the neuromodulatory system, including acetylcholine and noradrenaline, may ensure that such synaptic plasticity only occurs under specific neuromodulatory/behavioral states, such as learning or stress.

In addition to the synaptic plasticity, there is non-synaptic plasticity that is mediated by metabotropic glutamate receptors, acetylcholine receptors, or brain-derived 
neurotrophic factor (BDNF) in the subiculum (Graves et al., 2016; Moore et al., 2009). For example, BDNF enhances and depresses intrinsic excitability in subicular bursting and regular-spiking neurons, respectively (Graves et al., 2016). This variety of synaptic/non-synaptic plasticity suggests that the subiculum not only relays information from the hippocampus but may also actively participate in the processing of information in a unique manner.

\section{Behavioral function: contribution to memory}

Selectively lesioning the subiculum with minimal damage to the adjacent hippocampus is technically challenging, and only a handful lesion studies are available. One of the first lesion studies on the rodent subiculum investigated allocentric spatial memory in a water maze test (Morris et al., 1990). A neurotoxic lesion of either the subiculum or the hippocampus impaired the acquisition of spatial navigation, suggesting that both areas are necessary for allocentric spatial learning (Morris et al., 1990). A series of lesion studies on the dorsal subiculum further suggested the contribution of the subiculum to memory of idiothetic (i.e., self-motion) cues and spatial novelty (Potvin et al., 2010, 2007) as well as visual pattern separation (Potvin et al., 2009). Interestingly, lesion of either the subiculum or the hippocampus often impaired spatial memory to a similar degree, while concurrent lesion of both areas induced a more severe deficit than a single-area lesion (Morris et al., 1990; Potvin et al., 2007). This additive impairment suggests that the subiculum serves a unique spatial function that cannot be explained by a role merely as a downstream region of the hippocampus (Lever et al., 2009; Olson et al., 2016). Recently, an optogenetic study of dorsal subiculum-specific Cre transgenic mice revealed that the pathway from CA1 to dorsal subiculum to medial entorhinal cortex is crucial for hippocampus-dependent memory retrieval, but not for encoding (Roy et al., 2017). In contrast, the direct pathway from CA1 to medial entorhinal cortex is essential 
for memory encoding, but not for retrieval (Roy et al., 2017).

\section{Physiology: neural correlates of cognitive functions}

\subsection{Neural oscillations}

The hippocampus exhibits various types of extracellular neural oscillations including theta, gamma, and sharp wave/ripples (Bieri et al., 2014; Buzsáki, 2015, 2002; Chrobak and Buzsáki, 1996; Colgin, 2015; Colgin et al., 2009; Colgin and Moser, 2010; Igarashi et al., 2014; Kitanishi et al., 2015; Mizuseki et al., 2009; Mizuseki and Buzsaki, 2013). Each type of oscillation is tightly coupled with animal's behavior and sleep/wake cycles (Buzsáki, 2015, 2002; Colgin and Moser, 2010; Mizuseki and Miyawaki, 2017). These oscillations reflect gross electrical activity in the local network and typically accompany neuronal firing phase-locked to the ongoing oscillations. The synchronous firing of a neuronal population aligned to a certain oscillation potently excites postsynaptic neurons, thereby facilitating interregional transmission (Fell and Axmacher, 2011). Either during or over the course of learning a memory task, interregional oscillatory interactions are dynamically regulated in the hippocampus and parahippocampal areas (Kemere et al., 2013; Montgomery and Buzsáki, 2007; Yamamoto et al., 2014). Moreover, synaptic plasticity in the CA1 area regulates the development of phase-locked firing along a type of gamma oscillations inherited from the upstream CA3 area during a novel experience (Kitanishi et al., 2015), suggesting that synaptic plasticity controls interregional information transfer by regulating oscillatory interactions (Kitanishi et al., 2017).

Like the hippocampus, the subiculum also shows theta oscillations (Bullock et al., 1990), gamma oscillations (Chang and Huerta, 2012), and sharp wave/ripples (Anderson and O’Mara, 2003; Chrobak and Buzsáki, 1996) in vivo (Fig 2A). Moreover, accumulating evidence suggests that the subiculum may play a role in the generation of 
these oscillations. Theta oscillations $(4-10 \mathrm{~Hz})$ are generally associated with alert exploratory behavior and rapid eye movement (REM) sleep (Anderson and O'Mara, 2003; Buzsáki, 2002; Chang and Huerta, 2012), and are thought to be unidirectionally transmitted from the CA3 area to the downstream regions, CA1 area, and subiculum via an excitatory feedforward pathway. However, in isolated whole hippocampal preparation and during REM sleep in vivo, spontaneously generated theta oscillations within the subiculum are signaled backward to CA1 and CA3 areas, presumably through long-range GABAergic feedback projection (Jackson et al., 2014). How these distinct types of theta oscillations are organized remains to be elucidated. Interestingly, there is a greater increase in theta power in the subiculum when mice explore a novel object than a familiar object, which is not the case in the CA1 area (Chang and Huerta, 2012). In the hippocampus of freely-behaving animals, the spike timing of place cells progressively advances to earlier phases of extracellular theta cycles as the animal walks through the cell's place field, a phenomenon that is referred to as theta phase precession $\left(\mathrm{O}^{\prime} \mathrm{Keefe}\right.$ and Recce, 1993). The place field and theta phase precession are striking substrates of rate and temporal code of space, respectively, although it is still debated whether the two codes are intrinsically coupled (Harris et al., 2002; Mehta et al., 2002) or definitely independent (Huxter et al., 2003; Souza and Tort, 2017). Subicular principal cells show theta phase precession similar to the CA1 area (Kim et al., 2012).

In addition, the subiculum shows gamma oscillations in behaving rodents (Chang and Huerta, 2012). It has been suggested that the subiculum is the third spontaneous gamma generator in the hippocampal formation, in addition to the CA3 area and the entorhinal cortex because gamma oscillations have been observed even in the isolated subiculum (Jackson et al., 2011). Subicular gamma oscillations have at least two frequency bands that are distinctly modulated by theta oscillations: slow gamma 
oscillations $(25-50 \mathrm{~Hz})$ are mediated through excitatory and inhibitory mechanisms, whereas fast gamma oscillations $(100-150 \mathrm{~Hz})$ require rapid and strong local inhibition in the subiculum (Jackson et al., 2011; Menendez de la Prida, 2003). Whether subicular gamma oscillations mediate information flow from the hippocampal formation to multiple cortical and subcortical efferent areas is yet to be investigated.

Sharp wave/ripples occur in the hippocampus primarily during consummatory behavior, immobility, and slow-wave sleep (Buzsáki, 2015). Population bursts generated in recurrent CA3 circuits produce large transient field excitatory postsynaptic potentials in the termination zone of CA3 axons, such as the CA1 stratum radiatum and stratum oriens, that are observed as sharp waves (Buzsáki, 2015). Large depolarizations in CA1 pyramidal and inhibitory neurons induce a dynamic interaction among the activated neuronal ensemble, which consequently produces high-frequency $(150-250 \mathrm{~Hz})$ periodic field potentials — called ripples — in the stratum pyramidale (Stark et al., 2014; Ylinen et al., 1995). These sharp wave/ripple complexes are implicated in memory replay during sleep (Skaggs and McNaughton, 1996; Wilson and McNaughton, 1994) and during quiet wakefulness (Diba and Buzsáki, 2007; Foster and Wilson, 2006; Jadhav et al., 2012; Kudrimoti et al., 1999; Malvache et al., 2016). The content of such replay spans spatial (Lee and Wilson, 2002), episodic-like (Takahashi, 2015), and emotional modalities (Girardeau et al., 2017; Wu et al., 2017). Sharp wave/ripples are also reported in the output structures of the hippocampal formation, including the subiculum, presubiculum, and entorhinal cortex, of behaving rats (Anderson and O’Mara, 2003; Chrobak and Buzsáki, 1996) and can be observed in the subiculum of horizontal brain slices (Maslarova et al., 2015). In vitro electrophysiology has revealed that some subicular cells are activated before CA1 sharp wave occurrence (i.e., 'preceding' activity), while some others are activated after sharp waves (i.e., 'following' activity) (Norimoto et al., 2013). 
Surgical incision of the CA1-to-subiculum connection abolished the "following" but not "preceding" subicular activity (Norimoto et al., 2013). These results suggest that the subiculum is involved in both the generation and propagation of sharp wave/ripple complexes.

In contrast to extracellular studies, intracellular recordings—such as whole-cell recording and sharp electrode recording - enable us to investigate intracellular correlates of extracellular oscillations. Specifically, in vivo whole-cell recordings have demonstrated membrane potential dynamics at various frequency bands in the hippocampus, namely sub-theta $(\sim 3 \mathrm{~Hz})$ (Matsumoto et al., 2016), theta (Harvey et al., 2009), gamma (Penttonen et al., 1998), and ripples (English et al., 2014). In the subiculum, whole-cell and juxtacellular recordings in awake mice have revealed that, during CA1 ripples, bursting neurons and regular-spiking neurons are activated and inhibited, respectively, indicating that bursting neurons are preferentially used to output information during ripple events (Böhm et al., 2015). The intracellular dynamics of subicular neurons for other types of oscillations remain unknown.

\subsection{Single-cell representation}

One of the most striking firing patterns in the hippocampal formation occurs in spatial representation. The best characterized neural substrate of spatial representation is hippocampal place cells, which fire whenever an animal crosses a certain place in the environment (O'Keefe and Dostrovsky, 1971). Each of the hippocampal CA1, CA2, and CA3 areas has a different type of place coding (Alvernhe et al., 2008; Barnes et al., 1990; Hussaini et al., 2011; Lee et al., 2004a, 2004b; Lee and Knierim, 2007; Leutgeb et al., 2005, 2004; Mankin et al., 2015; Mizuseki et al., 2012; Park et al., 2011; Vazdarjanova and Guzowski, 2004).

Subicular neurons have also been shown to encode an animal's location in the 
environment (Fig. 2B). Approximately half of subicular pyramidal neurons show stable spatial firing across multiple light-dark transitions, suggesting that these neurons use egocentric cues to maintain their spatial representation (Brotons-Mas et al., 2010). In addition to rate coding, a fraction of subicular neurons is phase-locked to extracellular theta oscillations (Anderson and O'Mara, 2003) and exhibits robust theta phase precession (Kim et al., 2012).

The spatial code in the subiculum differs from that in the hippocampus in many ways. Subicular neurons generally have lower spatial selectivity (Barnes et al., 1990) and multiple place fields (Kim et al., 2012), contain a stronger directional signal (Sharp and Green, 1994), and rarely remap in two geometrically and visually distinctive contexts (Brotons-Mas et al., 2010; Sharp, 2006, 1997). Moreover, subicular neurons predict an animal's future location earlier than hippocampal neurons (Sharp, 1999). The spatial firing properties of subicular neurons are different along the proximodistal axis: neurons in the distal subiculum exhibit higher firing rates and spatial coherence as well as larger firing field sizes than those in the proximal subiculum (Kim et al., 2012; Sharp and Green, 1994). This proximal-distal difference in subicular firing may reflect the topographically biased inputs from the CA1 area and medial/lateral entorhinal cortices (Knierim et al., 2006). While hippocampal spatial codes are known to differ along the dorsoventral axis (Royer et al., 2010; Strange et al., 2014) and superficial-deep axis (Danielson et al., 2016; Geiller et al., 2017; Mallory and Giocomo, 2018; Mizuseki et al., 2011), how subicular spatial codes are organized along these axes remains unknown. Although some studies have classified subicular pyramidal units into bursting cells and non-bursting (i.e., presumably, regular-spiking) cells (Anderson and O’Mara, 2003; Gigg et al., 2000; Sharp and Green, 1994), similar to in vitro experiments (Menendez de la Prida, 2006), no differences in spatial firing properties between these two cell types have been found 
(Sharp and Green, 1994).

Besides place code, the dorsal subiculum represents other spatial and non-spatial properties including physical boundaries in a context (Brotons-Mas et al., 2017; Lever et al., 2009), the current axis of direction of movement (Olson et al., 2016), novel objects (Chang and Huerta, 2012), rewards (Martin and Ono, 2000), and working memory (Deadwyler and Hampson, 2004). These findings are briefly summarized below.

Based on computational models of the formation of hippocampal place fields, boundary vector cells that fire maximally when an environmental boundary is perceived at a certain distance and allocentric direction from the animal were predicted to exist (Barry et al., 2006). Later, the existence of such boundary vector cells was experimentally demonstrated by extracellular recordings from the dorsal subiculum (Lever et al., 2009) (Fig. 2B). Similarly, a portion of subicular cells demonstrate barrier-associated firing when a square open field is divided into four sub-chambers by inserting barriers. These neurons are called barrier-related cells (Brotons-Mas et al., 2017). When human subjects are located near physical boundaries in a virtual environment, strong theta oscillations are observed in the subiculum (Lee et al., 2018), which may reflect the firing of a neuronal population representing the physical boundaries. A recent study further demonstrated the role of the subiculum in the axis of travel (Olson et al., 2016), showing that approximately $9 \%$ of neurons in the dorsal subiculum discharge when an animal runs in a specific direction — as well as in the $180^{\circ}$ opposite direction — in a complicated maze with multiple interconnected tracks (Fig. 2B). This axis-tuned neural activity is lost in an open arena, and thus, thought to encode track segment orientation relative to physical boundaries. The subicular axis-tuned cells are distinct from head-direction cells abundant in parahippocampal areas (i.e., presubiculum, parasubiculum, and medial entorhinal cortex) because the head-direction cells in these areas typically represent only one orientation 
and maintain their directional tuning in an open arena (Boccara et al., 2010; Peyrache et al., 2017, 2015; Simonnet et al., 2017; Taube et al., 1990a, 1990b; Tukker et al., 2015).

One of the characteristic features of subicular spatial coding is multiplexed, conjunctive representation of space. While conjunctive spatial representations exist in the CA1 area (Acharya et al., 2016) and medial entorhinal cortex (Sargolini et al., 2006), the subiculum has a greater variety of such representations. For instance, axis-tuned neurons conjunctively encode routes and environmental boundaries (Olson et al., 2016), and boundary vector cells represent relationships among distance, allocentric direction, and boundary (Lever et al., 2009). Moreover, many place-tuned neurons in the subiculum also have directional selectivity (Sharp and Green, 1994), and subicular neurons with multiple place fields can be regarded as multiplexed place cells (Kim et al., 2012). As unitary spatial components such as place, head direction, distance, and boundary are all encoded in one synapse upstream of the subiculum (i.e., the CA1 area and entorhinal cortex), a unique role of the subiculum may be integrating various information into a compressed spatial code that can be efficiently read out by downstream areas (Kim et al., 2012). Through such integration, the subiculum may support spatial navigation, particularly in a large, complicated natural environment, that requires efficient binding of multiple types of spatial information.

In line with previous behavioral research (e.g., Potvin et al., 2010), it has been shown that when mice perform a novel object recognition task some subicular units fire at a higher rate for novel objects than familiar ones (Chang and Huerta, 2012; but see Anderson and O'Mara, 2004). Another example of non-spatially tuned neurons is related to reward. One-third of subicular neurons exhibit an anticipatory increase in firing in response to predictable rewards delivered by electric stimulation of the medial forebrain bundle, whereas a greater proportion of accumbens cells reacts in advance of rewards by 
increasing or decreasing their firing rates (Martin and Ono, 2000). However, such rewardrelated firing in the subiculum is absent when food is used as a reward (Barnes et al., 1990; Sharp and Green, 1994) presumably because food is a less powerful reward than direct stimulation of the medial forebrain bundle. It has also been shown that the subiculum and CA1 area fire in a shared but complementary manner when rats perform a delayed non-matching-to-place task with a retention delay varying from 1 to $30 \mathrm{~s}$ (Hampson et al., 1999). The firing response of the dorsal subiculum was associated with delays shorter than $15 \mathrm{~s}$, whereas dorsal CA1 neurons responded to longer delays (Deadwyler and Hampson, 2004), suggesting the complementary contribution of these two regions to working memory.

As summarized in this section, the spatial code in the subiculum shares some similarities with the hippocampal code, but contains more compressed, conjunctive representation. Moreover, the subiculum shows a variety of non-spatial code. As the literature on the subiculum grows, a more unified view of some of the apparently distinct subicular codes may emerge. Alternatively, the disparate subicular firing patterns may represent the fundamental heterogeneity of the subicular network function. In any case, there is extensive room for further research on this intriguing brain region.

\section{Summary and future perspectives}

Here, we reviewed the anatomy, plasticity, behavioral role, and activity patterns of the subiculum. While the subiculum has become a brain region of increasing research attention, there are many intriguing questions about the subiculum that remain to be answered. We herein suggest possible future perspectives.

(1) Input: A variety of information (e.g., space, time, object, novelty) is represented in the

CA1 area and medial/lateral entorhinal cortices, which are one synapse upstream of the 
subiculum. Determining what type of information in what upstream areas is transmitted to what parts/cells of the subiculum would help to comprehensively understand the network mechanisms of the subiculum.

(2) Intrinsic computation: The subicular pyramidal cells exhibit several forms of synaptic plasticity and form recurrent circuits. These network properties imply that the subiculum actively modifies and integrates inputs from upstream regions. Revealing what intrinsic computations are performed and, as a consequence, how neuronal information is distributed in bursting/non-bursting cells along the proximal-distal and superficial-deep axes would be a key step in uncovering the fundamental function of the subiculum.

(3) Output: The subiculum projects to multiple brain regions, but individual subicular neurons project to only one or a few of these target regions. Such a widespread, but specific, projection pattern raises the possibility that the subiculum sends distinct types of information to specific target areas. Revealing what information is output to what projection targets at each behavior/sleep state is crucial for understanding the impact of the hippocampal formation on downstream targets. 


\section{References}

Acharya, L., Aghajan, Z.M., Vuong, C., Moore, J.J., Mehta, M.R., 2016. Causal influence of visual cues on hippocampal directional selectivity. Cell 164, 197-207. doi:10.1016/j.cell.2015.12.015

Aggleton, J.P., Christiansen, K., 2015. The subiculum: the heart of the extended hippocampal system, Progress in Brain Research. Elsevier B.V. doi:10.1016/bs.pbr.2015.03.003

Aimone, J.B., Deng, W., Gage, F.H., 2011. Resolving new memories: a critical look at the dentate gyrus, adult neurogenesis, and pattern separation. Neuron 70, 589-596. doi:10.1016/j.neuron.2011.05.010

Alvernhe, A., Van Cauter, T., Save, E., Poucet, B., 2008. Different CA1 and CA3 representations of novel routes in a shortcut situation. J. Neurosci. 28, 7324-7333. doi:10.1523/JNEUROSCI.1909-08.2008

Amaral, D.G., Dolorfo, C., Alvarez-Royo, P., 1991. Organization of CA1 projections to the subiculum: a PHA-L analysis in the rat. Hippocampus 1, 415-435. doi:10.1002/hipo.450010410

Anderson, M., Commins, S., O’Mara, S.M., 2000. The effects of low frequency and two-pulse stimulation protocols on synaptic transmission in the CA1-subiculum pathway in the anaesthetized rat. Neurosci. Lett. 279, 181-184. doi:10.1016/S0304-3940(99)00996-9

Anderson, M.I., O’Mara, S.M., 2003. Analysis of recordings of single-unit firing and population activity in the dorsal subiculum of unrestrained, freely moving rats. J Neurophysiol 90, 655-665. doi:10.1152/jn.00723.2002

Barnes, C.A., McNaughton, B.L., Mizumori, S.J.Y., Leonard, B.W., Lin, L.H., 1990. Comparison of spatial and temporal characteristics of neuronal activity in sequential stages of hippocampal processing. Prog. Brain Res. 83, 287-300. doi:10.1016/S0079-6123(08)61257-1

Barry, C., Lever, C., Hayman, R., Hartley, T., Burton, S., O’Keefe, J., Jeffery, K., Burgess, N., 2006. The boundary vector cell model of place cell firing and spatial memory. Rev. Neurosci. 17, 71-98. doi:10.1515/REVNEURO.2006.17.1-2.71

Behr, J., Empson, R.M., Schmitz, D., Gloveli, T., Heinemann, U., 1997. Effects of serotonin on synaptic and intrinsic properties of rat subicular neurons in vitro. Brain Res. 773, 217-222. doi:10.1016/S0006-8993(97)00939-6

Behr, J., Empson, R.M., Schmitz, D., Gloveli, T., Heinemann, U., 1996. Electrophysiological properties of rat subicular neurons in vitro. Neurosci Lett 220, 41-44. doi:S0304394096132420 [pii]

Behr, J., Gloveli, T., Heinemann, U., 1998. The perforant path projection from the medial entorhinal cortex layer III to the subiculum in the rat combined 
hippocampal-entorhinal cortex slice. Eur. J. Neurosci. 10, 1011-1018. doi:10.1046/j.1460-9568.1998.00111.x

Behr, J., Wozny, C., Fidzinski, P., Schmitz, D., 2009. Synaptic plasticity in the subiculum. Prog. Neurobiol. 89, 334-342. doi:10.1016/j.pneurobio.2009.09.002

Berger, T.W., Swanson, G.W., Milner, T.A., Lynch, G.S., Thompson, R.F., 1980.

Reciprocal anatomical connections between hippocampus and subiculum in the rabbit: evidence for subicular innervation of regio superior. Brain Res. 183, 265276. doi:10.1016/0006-8993(80)90463-1

Berns, D.S., DeNardo, L.A., Pederick, D.T., Luo, L., 2018. Teneurin-3 controls topographic circuit assembly in the hippocampus. Nature. doi:10.1038/nature25463

Bieri, K.W., Bobbitt, K.N., Colgin, L.L., 2014. Slow and fast gamma rhythms coordinate different spatial coding modes in hippocampal place cells. Neuron 82, 670-681. doi:10.1016/j.neuron.2014.03.013

Bliss, T.V.P., Lømo, T., 1973. Long-lasting potentiation of synaptic transmission in the dentate area of the anaesthetized rabbit following stimulation of the perforant path. J. Physiol. 232, 331-356. doi:10.1113/jphysiol.1973.sp010273

Boccara, C.N., Sargolini, F., Thoresen, V.H., Solstad, T., Witter, M.P., Moser, E.I., Moser, M.-B., 2010. Grid cells in pre- and parasubiculum. Nat. Neurosci. 13, 987994. doi:10.1038/nn.2602

Boeijinga, P.H., Boddeke, H.W.G.M., 1996. Activation of 5-HT1B receptors suppresses low but not high frequency synaptic transmission in the rat subicular cortex in vitro. Brain Res. 721, 59-65. doi:10.1016/0006-8993(96)00149-7

Böhm, C., Peng, Y., Maier, N., Winterer, J., Poulet, J.F.A., Geiger, J.R.P., Schmitz, D., 2015. Functional diversity of subicular principal cells during hippocampal ripples. J. Neurosci. 35, 13608-13618. doi:10.1523/JNEUROSCI.5034-14.2015

Brotons-Mas, J.R., Montejo, N., O’Mara, S.M., Sanchez-Vives, M. V., 2010. Stability of subicular place fields across multiple light and dark transitions. Eur. J. Neurosci. 32, 648-658. doi:10.1111/j.1460-9568.2010.07308.x

Brotons-Mas, J.R., Schaffelhofer, S., Guger, C., O’Mara, S.M., Sanchez-Vives, M. V., 2017. Heterogeneous spatial representation by different subpopulations of neurons in the subiculum. Neuroscience 343, 174-189. doi:10.1016/j.neuroscience.2016.11.042

Bubb, E.J., Kinnavane, L., Aggleton, J.P., 2017. Hippocampal-diencephalic-cingulate networks for memory and emotion: an anatomical guide. Brain Neurosci. Adv. 1, 239821281772344. doi:10.1177/2398212817723443

Bullock, T.H., Buzsáki, G., McClune, M.C., 1990. Coherence of compound field potentials reveals discontinuities in the CA1-subiculum of the hippocampus in 
freely-moving rats. Neuroscience 38, 609-619. doi:10.1016/0306-4522(90)900559

Buzsáki, G., 2015. Hippocampal sharp wave-ripple: a cognitive biomarker for episodic memory and planning. Hippocampus 25, 1073-1188. doi:10.1002/hipo.22488

Buzsáki, G., 2002. Theta oscillations in the hippocampus. Neuron 33, 325-340. doi:10.1016/S0896-6273(02)00586-X

Buzsáki, G., 1996. The hippocampo-neocortical dialogue. Cereb. Cortex. doi:10.1093/cercor/6.2.81

Cembrowski, M.S., Phillips, M.G., DiLisio, S.F., Shields, B.C., Winnubst, J., Chandrashekar, J., Bas, E., Spruston, N., 2018. Dissociable structural and functional hippocampal outputs via distinct subiculum cell classes. Cell 1-13. doi:10.1016/j.cell.2018.03.031

Chang, E.H., Huerta, P.T., 2012. Neurophysiological correlates of object recognition in the dorsal subiculum. Front. Behav. Neurosci. 6. doi:10.3389/fnbeh.2012.00046

Christiansen, K., Dillingham, C.M., Wright, N.F., Saunders, R.C., Vann, S.D., Aggleton, J.P., 2016. Complementary subicular pathways to the anterior thalamic nuclei and mammillary bodies in the rat and macaque monkey brain. Eur. J. Neurosci. 43, 1044-1061. doi:10.1111/ejn.13208

Chrobak, J.J., Buzsáki, G., 1996. High-frequency oscillations in the output networks of the hippocampal-entorhinal axis of the freely behaving rat. J. Neurosci. 16, 30563066.

Clark, B.J., Taube, J.S., 2012. Vestibular and attractor network basis of the head direction cell signal in subcortical circuits. Front. Neural Circuits 6. doi:10.3389/fncir.2012.00007

Colgin, L.L., 2015. Theta-gamma coupling in the entorhinal-hippocampal system. Curr. Opin. Neurobiol. 31, 45-50. doi:10.1016/j.conb.2014.08.001

Colgin, L.L., Denninger, T., Fyhn, M., Hafting, T., Bonnevie, T., Jensen, O., Moser, M.-B., Moser, E.I., 2009. Frequency of gamma oscillations routes flow of information in the hippocampus. Nature 462, 353-357. doi:10.1038/nature08573

Colgin, L.L., Moser, E.I., 2010. Gamma oscillations in the hippocampus. Physiology 25, 319-329. doi:10.1152/physiol.00021.2010

Commins, S., Gigg, J., Anderson, M., O’Mara, S.M., 1998. The projection from hippocampal area CA1 to the subiculum sustains long-term potentiation. Neuroreport 9, 847-50. doi:10.1097/00001756-199803300-00015

Cooper, D.C., Chung, S., Spruston, N., 2005. Output-mode transitions are controlled by prolonged inactivation of sodium channels in pyramidal neurons of subiculum. PLoS Biol. 3, 1123-1129. doi:10.1371/journal.pbio.0030175

Danielson, N.B., Zaremba, J.D., Kaifosh, P., Bowler, J., Ladow, M., Losonczy, A., 
2016. Sublayer-specific coding dynamics during spatial navigation and learning in hippocampal area CA1. Neuron 91, 652-665. doi:10.1016/j.neuron.2016.06.020

Deadwyler, S.A., Hampson, R.E., 2004. Differential but complementary mnemonic functions of the hippocampus and subiculum. Neuron 42, 465-476. doi:10.1016/S0896-6273(04)00195-3

Deshpande, A., Bergami, M., Ghanem, A., Conzelmann, K.-K., Lepier, A., Gotz, M., Berninger, B., 2013. Retrograde monosynaptic tracing reveals the temporal evolution of inputs onto new neurons in the adult dentate gyrus and olfactory bulb. Proc. Natl. Acad. Sci. 110, E1152-E1161. doi:10.1073/pnas.1218991110

Diba, K., Buzsáki, G., 2007. Forward and reverse hippocampal place-cell sequences during ripples. Nat. Neurosci. 10, 1241-1242. doi:10.1038/nn1961

Dillingham, C.M., Erichsen, J.T., O’Mara, S.M., Aggleton, J.P., Vann, S.D., 2015. Fornical and nonfornical projections from the rat hippocampal formation to the anterior thalamic nuclei. Hippocampus 25, 977-992. doi:10.1002/hipo.22421

Ding, S.L., 2013. Comparative anatomy of the prosubiculum, subiculum, presubiculum, postsubiculum, and parasubiculum in human, monkey, and rodent. J. Comp. Neurol. 521, 4145-4162. doi:10.1002/cne.23416

Dudek, S.M., Bear, M.F., 1992. Homosynaptic long-term depression in area CA1 of hippocampus and effects of N-methyl-D-aspartate receptor blockade. Proc. Natl. Acad. Sci. 89, 4363-4367. doi:10.1073/pnas.89.10.4363

English, D.F., Peyrache, A., Stark, E., Roux, L., Vallentin, D., Long, M.A., Buzsáki, G., 2014. Excitation and inhibition compete to control spiking during hippocampal ripples: Intracellular study in behaving mice. J. Neurosci. 34, 16509-16517. doi:10.1523/JNEUROSCI.2600-14.2014

Fell, J., Axmacher, N., 2011. The role of phase synchronization in memory processes. Nat. Rev. Neurosci. 12, 105-118. doi:10.1038/nrn2979

Fidzinski, P., Shor, O., Behr, J., 2008. Target-cell-specific bidirectional synaptic plasticity at hippocampal output synapses. Eur. J. Neurosci. 27, 1111-1118. doi:10.1111/j.1460-9568.2008.06089.x

Foster, D.J., Wilson, M.A., 2006. Reverse replay of behavioural sequences in hippocampal place cells during the awake state. Nature 440, 680-683. doi:10.1038/nature04587

Fujise, N., Hunziker, W., Heizmann, C.W., Kosaka, T., 1995. Distribution of the calcium binding proteins, calbindin D-28K and parvalbumin, in the subicular complex of the adult mouse. Neurosci. Res. 22, 89-107. doi:10.1016/01680102(95)00882-T

Geiller, T., Fattahi, M., Choi, J.S., Royer, S., 2017. Place cells are more strongly tied to landmarks in deep than in superficial CA1. Nat. Commun. 8. 
doi:10.1038/ncomms14531

Gigg, J., Finch, D.M., O’Mara, S.M., 2000. Responses of rat subicular neurons to convergent stimulation of lateral entorhinal cortex and CA1 in vivo. Brain Res. 884, 35-50. doi:10.1016/S0006-8993(00)02878-X

Giocomo, L.M., Zilli, E.A., Fransén, E., Hasselmo, M.E., 2007. Temporal frequency of subthreshold oscillations scales with entorhinal grid cell field spacing. Science (80-. ). 315, 1719-1722. doi:10.1126/science.1139207

Girardeau, G., Inema, I., Buzsáki, G., 2017. Reactivations of emotional memory in the hippocampus-amygdala system during sleep. Nat. Neurosci. doi:10.1038/nn.4637

Graves, A.R., Moore, S.J., Bloss, E.B., Mensh, B.D., Kath, W.L., Spruston, N., 2012. Hippocampal pyramidal neurons comprise two distinct cell types that are countermodulated by metabotropic receptors. Neuron 76, 776-789. doi:10.1016/j.neuron.2012.09.036

Graves, A.R., Moore, S.J., Spruston, N., Tryba, A.K., Kaczorowski, C.C., 2016. Brainderived neurotrophic factor differentially modulates excitability of two classes of hippocampal output neurons. J. Neurophysiol. 116, 466-471. doi:10.1152/jn.00186.2016

Greene, J.R.T., Totterdell, S., 1997. Morphology and distribution of electrophysiologically defined classes of pyramidal and nonpyramidal neurons in rat ventral subiculum in vitro. J. Comp. Neurol. 380, 395-408. doi:10.1002/(SICI)1096-9861(19970414)380:3<395::AID-CNE8>3.0.CO;2-Y

Groenewegen, H.J., Vermeulen-Van der Zee, E., te Kortschot, A., Witter, M.P., 1987. Organization of the projections from the subiculum to the ventral striatum in the rat. A study using anterograde transport of Phaseolus vulgaris leucoagglutinin. Neuroscience 23, 103-120. doi:10.1016/0306-4522(87)90275-2

Hampson, R.E., Jarrard, L.E., Deadwyler, S.A., 1999. Effects of ibotenate hippocampal and extrahippocampal destruction on delayed-match and -nonmatch-to-sample behavior in rats. J. Neurosci. 19, 1492-1507.

Harris, E., Stewart, M., 2001a. Intrinsic connectivity of the rat subiculum: II. Properties of synchronous spontaneous activity and a demonstration of multiple generator regions. J. Comp. Neurol. 435, 506-518. doi:10.1002/cne.1047

Harris, E., Stewart, M., 2001b. Propagation of synchronous epileptiform events from subiculum backward into area CA1 of rat brain slices. Brain Res. 895, 41-49. doi:10.1016/S0006-8993(01)02023-6

Harris, E., Witter, M.P., Weinstein, G., Stewart, M., 2001. Intrinsic connectivity of the rat subiculum: I. Dendritic morphology and patterns of axonal arborization by pyramidal neurons. J. Comp. Neurol. 435, 490-505. doi:10.1002/cne.1046

Harris, K.D., Henze, D.A., Hirase, H., Leinekugel, X., Dragoi, G., Czurkó, A., Buzsáki, 
G., 2002. Spike train dynamics predicts theta-related phase precession in hippocampal pyramidal cells. Nature 417, 2116-2118. doi:10.1038/nature00808

Harvey, C.D., Collman, F., Dombeck, D.A., Tank, D.W., 2009. Intracellular dynamics of hippocampal place cells during virtual navigation. Nature 461, 941-946. doi:10.1038/nature08499

Honda, Y., Furuta, T., Kaneko, T., Shibata, H., Sasaki, H., 2011. Patterns of axonal collateralization of single layer $\mathrm{V}$ cortical projection neurons in the rat presubiculum. J. Comp. Neurol. 519, 1395-1412. doi:10.1002/cne.22578

Honda, Y., Ishizuka, N., 2015. Topographic distribution of cortical projection cells in the rat subiculum. Neurosci. Res. 92, 1-20. doi:10.1016/j.neures.2014.11.011

Honda, Y., Ishizuka, N., 2004. Organization of connectivity of the rat presubiculum: I. Efferent projections to the medial entorhinal cortex. J. Comp. Neurol. 473, 463484. doi:10.1002/cne.20093

Honda, Y., Sasaki, H., Umitsu, Y., Ishizuka, N., 2012. Zonal distribution of perforant path cells in layer III of the entorhinal area projecting to CA1 and subiculum in the rat. Neurosci. Res. 74, 200-209. doi:10.1016/j.neures.2012.10.005

Honda, Y., Umitsu, Y., Ishizuka, N., 2008. Organization of connectivity of the rat presubiculum: II. Associational and commissural connections. J. Comp. Neurol. 506, 640-658. doi:10.1002/cne.21572

Huang, Y.-Y., Kandel, E.R., 2005. Theta frequency stimulation up-regulates the synaptic strength of the pathway from CA1 to subiculum region of hippocampus. Proc. Natl. Acad. Sci. U. S. A. 102, 232-237. doi:10.1073/pnas.0408368102

Hunsaker, M.R., Kesner, R.P., 2018. Unfolding the cognitive map: the role of hippocampal and extra-hippocampal substrates based on a systems analysis of spatial processing. Neurobiol. Learn. Mem. doi:10.1016/j.nlm.2017.11.012

Hussaini, S.A., Kempadoo, K.A., Thuault, S.J., Siegelbaum, S.A., Kandel, E.R., 2011. Increased size and stability of CA1 and CA3 place fields in HCN1 knockout mice. Neuron 72, 643-653. doi:10.1016/j.neuron.2011.09.007

Huxter, J., Burgess, N., O’Keefe, J., 2003. Independent rate and temporal coding in hippocampal pyramidal cells. Nature 425, 828-832. doi:10.1038/nature02058

Igarashi, K.M., Lu, L., Colgin, L.L., Moser, M.-B., Moser, E.I., 2014. Coordination of entorhinal-hippocampal ensemble activity during associative learning. Nature 510, 143-147. doi:10.1038/nature13162

Ishihara, Y., Fukuda, T., 2016. Immunohistochemical investigation of the internal structure of the mouse subiculum. Neuroscience 337, 242-266. doi:10.1016/j.neuroscience.2016.09.027

Ishizuka, N., 2001. Laminar organization of the pyramidal cell layer of the subiculum in the rat. J. Comp. Neurol. 435, 89-110. doi:10.1002/cne.1195 
Jackson, J., Amilhon, B., Goutagny, R., Bott, J.-B., Manseau, F., Kortleven, C., Bressler, S.L., Williams, S., 2014. Reversal of theta rhythm flow through intact hippocampal circuits. Nat. Neurosci. 17, 1362-1370. doi:10.1038/nn.3803

Jackson, J., Goutagny, R., Williams, S., 2011. Fast and slow gamma rhythms are intrinsically and independently generated in the subiculum. J. Neurosci. 31, 12104-12117. doi:10.1523/JNEUROSCI.1370-11.2011

Jadhav, S.P., Kemere, C., German, P.W., Frank, L.M., 2012. Awake hippocampal sharp-wave ripples support spatial memory. Science (80-. ). 336, 1454-1458. doi:10.1126/science. 1217230

Jankowski, M.M., Ronnqvist, K.C., Tsanov, M., Vann, S.D., Wright, N.F., Erichsen, J.T., Aggleton, J.P., O’Mara, S.M., 2013. The anterior thalamus provides a subcortical circuit supporting memory and spatial navigation. Front. Syst. Neurosci. 7. doi:10.3389/fnsys.2013.00045

Jarsky, T., Mady, R., Kennedy, B., Spruston, N., 2008. Distribution of bursting neurons in the CA1 region and the subiculum of the rat hippocampus. J Comp Neurol 506, 535-547. doi:10.1002/cne

Jung, H.Y., Staff, N.P., Spruston, N., 2001. Action potential bursting in subicular pyramidal neurons is driven by a calcium tail current. J. Neurosci. 21, 3312-3321. doi:21/10/3312 [pii]

Kawaguchi, Y., Hama, K., 1987a. Two subtypes of non-pyramidal cells in rat hippocampal formation identified by intracellular recording and HRP injection. Brain Res. 411, 190-195. doi:10.1016/0006-8993(87)90700-1

Kawaguchi, Y., Hama, K., 1987b. Fast-spiking non-pyramidal cells in the hippocampal CA3 region, dentate gyrus and subiculum of rats. Brain Res. 425, 351-355. doi:10.1016/0006-8993(87)90518-X

Kemere, C., Carr, M.F., Karlsson, M.P., Frank, L.M., 2013. Rapid and continuous modulation of hippocampal network state during exploration of new places. PLoS One 8, e73114. doi:10.1371/journal.pone.0073114

Kim, S.M., Ganguli, S., Frank, L.M., 2012. Spatial information outflow from the hippocampal circuit: distributed spatial coding and phase precession in the subiculum. J. Neurosci. 32, 11539-11558. doi:10.1523/JNEUROSCI.594211.2012

Kim, Y., Spruston, N., 2012. Target-specific output patterns are predicted by the distribution of regular-spiking and bursting pyramidal neurons in the subiculum. Hippocampus 22, 693-706. doi:10.1002/hipo.20931

Kinnavane, L., Vann, S.D., Nelson, A.J.D., O’mara, S.M., Aggleton, J.P., 2018. Collateral projections innervate the mammillary bodies and retrosplenial cortex: a new category of hippocampal cells 10, 383-17. doi:10.1523/ENEURO.0383- 
17.2018

Kishi, T., Tsumori, T., Ono, K., Yokota, S., Ishino, H., Yasui, Y., 2000. Topographical organization of projections from the subiculum to the hypothalamus in the rat. J. Comp. Neurol. 419, 205-222. doi:10.1002/(SICI)10969861(20000403)419:2<205::AID-CNE5>3.0.CO;2-0

Kitamura, T., Pignatelli, M., Suh, J., Kohara, K., Yoshiki, A., Abe, K., Tonegawa, S., 2014. Island cells control temporal association memory. Science (80-. ). 343, 896901. doi:10.1126/science. 1244634

Kitanishi, T., Ito, H.T., Hayashi, Y., Shinohara, Y., Mizuseki, K., Hikida, T., 2017. Network mechanisms of hippocampal laterality, place coding, and goal-directed navigation. J. Physiol. Sci. doi:10.1007/s12576-016-0502-Z

Kitanishi, T., Ujita, S., Fallahnezhad, M., Kitanishi, N., Ikegaya, Y., Tashiro, A., 2015. Novelty-induced phase-locked firing to slow gamma oscillations in the hippocampus: requirement of synaptic plasticity. Neuron 86, 1265-1276. doi:10.1016/j.neuron.2015.05.012

Kloosterman, F., Witter, M.P., Van Haeften, T., 2003. Topographical and laminar organization of subicular projections to the parahippocampal region of the rat. $\mathrm{J}$. Comp. Neurol. 455, 156-171. doi:10.1002/cne.10472

Knierim, J.J., Lee, I., Hargreaves, E.L., 2006. Hippocampal place cells: parallel input streams, subregional processing, and implications for episodic memory. Hippocampus 16, 755-764. doi:10.1002/hipo.20203

Knierim, J.J., Zhang, K., 2012. Attractor dynamics of spatially correlated neural activity in the limbic system. Annu. Rev. Neurosci. 35, 267-286. doi:10.1146/annurevneuro-062111-150351

Knopp, A., Frahm, C., Fidzinski, P., Witte, O.W., Behr, J., 2008. Loss of GABAergic neurons in the subiculum and its functional implications in temporal lobe epilepsy. Brain 131, 1516-1527. doi:10.1093/brain/awn095

Knopp, A., Kivi, A., Wozny, C., Heinemann, U., Behr, J., 2005. Cellular and network properties of the subiculum in the pilocarpine model of temporal lobe epilepsy. J. Comp. Neurol. 483, 476-88. doi:10.1002/cne.20460

Köhler, C., 1985. Intrinsic projections of the retrohippocampal region in the rat brain. I. The subicular complex. J. Comp. Neurol. 236, 504-522. doi:10.1002/cne.902360407

Köhler, C., Wu, J.Y., Chan-Palay, V., 1985. Neurons and terminals in the retrohippocampal region in the rat's brain identified by anti- $\gamma$-aminobutyric acid and anti-glutamic acid decarboxylase immunocytochemistry. Anat. Embryol. (Berl). 173, 35-44. doi:10.1007/BF00707302

Kudrimoti, H.S., Barnes, C.A., McNaughton, B.L., 1999. Reactivation of hippocampal 
cell assemblies: effects of behavioral state, experience, and EEG dynamics. J. Neurosci. 19, 4090-4101.

Kunitake, A., Kunitake, T., Stewart, M., 2004. Differential modulation by carbachol of four separate excitatory afferent systems to the rat subiculum in vitro. Hippocampus 14, 986-999. doi:10.1002/hipo.20016

Leão, R.N., Mikulovic, S., Leão, K.E., Munguba, H., Gezelius, H., Enjin, A., Patra, K., Eriksson, A., Loew, L.M., Tort, A.B.L., Kullander, K., 2012. OLM interneurons differentially modulate CA3 and entorhinal inputs to hippocampal CA1 neurons. Nat. Neurosci. 15, 1524-1530. doi:10.1038/nn.3235

Lee, A.K., Wilson, M.A., 2002. Memory of sequential experience in the hippocampus during slow wave sleep. Neuron 36, 1183-1194. doi:10.1016/S08966273(02)01096-6

Lee, I., Knierim, J.J., 2007. The relationship between the field-shifting phenomenon and representational coherence of place cells in CA1 and CA3 in a cue-altered environment. Learn. Mem. 14, 807-815. doi:10.1101/lm.706207

Lee, I., Rao, G., Knierim, J.J., 2004a. A double dissociation between hippocampal subfields: differential time course of CA3 and CA1 place cells for processing changed environments. Neuron 42, 803-815. doi:10.1016/j.neuron.2004.05.010

Lee, I., Yoganarasimha, D., Rao, G., Knierim, J.J., 2004b. Comparison of population coherence of place cells in hippocampal subfields CA1 and CA3. Nature 430, 456459. doi:10.1038/nature02739

Lee, S.A., Miller, J.F., Watrous, A.J., Sperling, M., Sharan, A., Worrell, G.A., Berry, B.M., Jobst, B.C., Davis, K.A., Gross, R.E., Lega, B., Sheth, S., Das, S.R., Stein, J.M., Gorniak, R., Rizzuto, D.S., Jacobs, J., 2018. Electrophysiological signatures of spatial boundaries in the human subiculum. J. Neurosci. 38, 3265-3272. doi:10.1101/218040

Lein, E.S., Zhao, X., Gage, F.H., 2004. Defining a molecular atlas of the hippocampus using DNA microarrays and high-throughput in situ hybridization. J. Neurosci. 24, 3879-3889. doi:10.1523/JNEUROSCI.4710-03.2004

Leutgeb, S., Leutgeb, J.K., Barnes, C.A., Moser, E.I., McNaughton, B.L., Moser, M.-B., 2005. Independent codes for spatial and episodic memory in hippocampal neuronal ensembles. Science (80-. ). 309, 619-623. doi:10.1126/science.1114037

Leutgeb, S., Leutgeb, J.K., Treves, A., Moser, M.-B., Moser, E.I., 2004. Distinct ensemble codes in hippocampal areas CA3 and CA1. Science (80-. ). 305, 12951298. doi:10.1126/science. 1100265

Lever, C., Burton, S., Jeewajee, A., O’Keefe, J., Burgess, N., 2009. Boundary vector cells in the subiculum of the hippocampal formation. J. Neurosci. 29, 9771-9777. doi:10.1523/JNEUROSCI.1319-09.2009 
Li, H., Zhang, J., Xiong, W., Xu, T., Cao, J., Xu, L., 2005. Long-term depression in rat CA1-subicular synapses depends on the G-protein coupled mACh receptors. Neurosci. Res. 52, 287-294. doi:10.1016/j.neures.2005.04.002

Macdougall, M.J., Howland, J.G., 2013. Acute stress and hippocampal output: exploring dorsal CA1 and subicular synaptic plasticity simultaneously in anesthetized rats. Physiol. Rep. 1. doi:10.1002/phy2.35

Mallory, C.S., Giocomo, L.M., 2018. Heterogeneity in hippocampal place coding. Curr. Opin. Neurobiol. doi:10.1016/j.conb.2018.02.014

Malvache, A., Reichinnek, S., Villette, V., Haimerl, C., Cossart, R., 2016. Awake hippocampal reactivations project onto orthogonal neuronal assemblies. Science (80-. ). 353, 1280-1283. doi:10.1126/science.aaf3319

Mankin, E.A., Diehl, G.W., Sparks, F.T., Leutgeb, S., Leutgeb, J.K., 2015. Hippocampal CA2 activity patterns change over time to a larger extent than between spatial contexts. Neuron 85, 190-202. doi:10.1016/j.neuron.2014.12.001

Martin, P.D., Ono, T., 2000. Effects of reward anticipation, reward presentation, and spatial parameters on the firing of single neurons recorded in the subiculum and nucleus accumbens of freely moving rats. Behav. Brain Res. 116, 23-38. doi:10.1016/S0166-4328(00)00249-7

Maslarova, A., Lippmann, K., Salar, S., Rösler, A., Heinemann, U., 2015. Differential participation of pyramidal cells in generation of spontaneous sharp wave-ripples in the mouse subiculum in vitro. Neurobiol. Learn. Mem. 125, 113-119. doi:10.1016/j.nlm.2015.08.008

Mathiasen, M.L., Dillingham, C.M., Kinnavane, L., Powell, A.L., Aggleton, J.P., 2017. Asymmetric cross-hemispheric connections link the rat anterior thalamic nuclei with the cortex and hippocampal formation. Neuroscience 349, 128-143. doi:10.1016/j.neuroscience.2017.02.026

Matsumoto, N., Okamoto, K., Takagi, Y., Ikegaya, Y., 2016. 3-Hz subthreshold oscillations of CA2 neurons in vivo. Hippocampus 26, 1570-1578. doi:10.1002/hipo.22657

Mattia, D., Kawasaki, H., Avoli, M., 1997. In vitro electrophysiology of rat subicular bursting neurons. Hippocampus 7, 48-57. doi:10.1002/(SICI)10981063(1997)7:1<48::AID-HIPO5>3.0.CO;2-3

McNaughton, N., 2006. The role of the subiculum within the behavioural inhibition system. Behav. Brain Res. doi:10.1016/j.bbr.2006.05.037

Mehta, M.R., Lee, A.K., Wilson, M.A., 2002. Role of experience and oscillations in transforming a rate code into a temporal code. Nature 417, 741-746. doi:10.1038/nature00807

Menendez de la Prida, L., 2006. Functional features of the rat subicular microcircuits 
studied in vitro. Behav. Brain Res. 174, 198-205. doi:10.1016/j.bbr.2006.05.033

Menendez de la Prida, L., 2003. Control of bursting by local inhibition in the rat subiculum in vitro. J. Physiol. 549, 219-230. doi:10.1113/jphysiol.2003.039305

Menendez de la Prida, L., Suarez, F., Pozo, M.A., 2003. Electrophysiological and morphological diversity of neurons from the rat subicular complex in vitro. Hippocampus. doi:10.1002/hipo.10123

Mizuseki, K., Buzsaki, G., 2013. Theta oscillations decrease spike synchrony in the hippocampus and entorhinal cortex. Philos. Trans. R. Soc. B Biol. Sci. 369, 20120530-20120530. doi:10.1098/rstb.2012.0530

Mizuseki, K., Diba, K., Pastalkova, E., Buzsáki, G., 2011. Hippocampal CA1 pyramidal cells form functionally distinct sublayers. Nat. Neurosci. 14, 1174-1181. doi:10.1038/nn.2894

Mizuseki, K., Miyawaki, H., 2017. Hippocampal information processing across sleep/wake cycles. Neurosci. Res. doi:10.1016/j.neures.2017.04.018

Mizuseki, K., Royer, S., Diba, K., Buzsáki, G., 2012. Activity dynamics and behavioral correlates of CA3 and CA1 hippocampal pyramidal neurons. Hippocampus 22, 1659-1680. doi:10.1002/hipo.22002

Mizuseki, K., Sirota, A., Pastalkova, E., Buzsáki, G., 2009. Theta oscillations provide temporal windows for local circuit computation in the entorhinal-hippocampal loop. Neuron 64, 267-280. doi:10.1016/j.neuron.2009.08.037

Montgomery, S.M., Buzsáki, G., 2007. Gamma oscillations dynamically couple hippocampal CA3 and CA1 regions during memory task performance. Proc. Natl. Acad. Sci. 104, 14495-14500. doi:10.1073/pnas.0701826104

Moore, S.J., Cooper, D.C., Spruston, N., 2009. Plasticity of burst firing induced by synergistic activation of metabotropic glutamate and acetylcholine receptors. Neuron 61, 287-300. doi:10.1016/j.neuron.2008.12.013

Morris, R.G.M., Schenk, F., Tweedie, F., Jarrard, L.E., 1990. Ibotenate lesions of hippocampus and/or subiculum: dissociating components of allocentric spatial learning. Eur. J. Neurosci. 2, 1016-1028. doi:10.1111/j.1460-9568.1990.tb00014.x

Mulkey, R.M., Malenka, R.C., 1992. Mechanisms underlying induction of homosynaptic long-term depression in area CA1 of the hippocampus. Neuron 9, 967-975. doi:10.1016/0896-6273(92)90248-C

Naber, P.A., Witter, M.P., 1998. Subicular efferents are organized mostly as parallel projections: a double-labeling, retrograde-tracing study in the rat. J. Comp. Neurol. 393, 284-297. doi:10.1002/(SICI)1096-9861(19980413)393:3<284::AIDCNE2>3.0.CO;2-Y

Nakashiba, T., Cushman, J.D., Pelkey, K. a, Renaudineau, S., Buhl, D.L., McHugh, T.J., Rodriguez Barrera, V., Chittajallu, R., Iwamoto, K.S., McBain, C.J., 
Fanselow, M.S., Tonegawa, S., 2012. Young dentate granule cells mediate pattern separation, whereas old granule cells facilitate pattern completion. Cell 149, 188201. doi:10.1016/j.cell.2012.01.046

Namura, S., Takada, M., Kikuchi, H., Mizuno, N., 1994. Topographical organization of subicular neurons projecting to subcortical regions. Brain Res. Bull. 35, 221-231. doi:10.1016/0361-9230(94)90126-0

Nichol, H., Amilhon, B., Manseau, F., Badrinarayanan, S., Williams, S., 2018. Electrophysiological and morphological characterization of Chrna2 cells in the subiculum and CA1 of the hippocampus: an optogenetic investigation. Front. Cell. Neurosci. 12, 1-14. doi:10.3389/fncel.2018.00032

Norimoto, H., Matsumoto, N., Miyawaki, T., Matsuki, N., Ikegaya, Y., 2013. Subicular activation preceding hippocampal ripples in vitro. Sci. Rep. 3, 2696. doi:10.1038/srep02696

O’Keefe, J., Dostrovsky, J., 1971. The hippocampus as a spatial map. preliminary evidence from unit activity in the freely-moving rat. Brain Res. 34, 171-175. doi:10.1016/0006-8993(71)90358-1

O’Keefe, J., Recce, M.L., 1993. Phase relationship between hippocampal place units and the EEG theta rhythm. Hippocampus 3, 317-330. doi:10.1002/hipo.450030307

O'Mara, S., 2005. The subiculum: what it does, what it might do, and what neuroanatomy has yet to tell us. J. Anat. 207, 271-282. doi:10.1111/j.14697580.2005.00446.x

O’Mara, S.M., Commins, S., Anderson, M., 2000. Synaptic plasticity in the hippocampal area CA1-subiculum projection: implications for theories of memory. Hippocampus 10, 447-456. doi:10.1002/1098-1063(2000)10:4<447::AIDHIPO11>3.0.CO;2-2

O’Mara, S.M., Commins, S., Anderson, M., Gigg, J., 2001. The subiculum: a review of form, physiology and function. Prog. Neurobiol. 64, 129-155. doi:10.1016/S03010082(00)00054-X

O’Reilly, K.C., Gulden Dahl, A., Ulsaker Kruge, I., Witter, M.P., 2013. Subicularparahippocampal projections revisited: development of a complex topography in the rat. J. Comp. Neurol. 521, 4284-4299. doi:10.1002/cne.23417

Olson, J.M., Tongprasearth, K., Nitz, D.A., 2016. Subiculum neurons map the current axis of travel. Nat. Neurosci. 20, 170-172. doi:10.1038/nn.4464

Panuccio, G., Vicini, S., Avoli, M., 2012. Cell type-specific properties of subicular GABAergic currents shape hippocampal output firing mode. PLoS One 7, 1-9. doi:10.1371/journal.pone.0050241

Park, E., Dvorak, D., Fenton, A.A., 2011. Ensemble place codes in hippocampus: CA1, $\mathrm{CA} 3$, and dentate gyrus place cells have multiple place fields in large 
environments. PLoS One 6. doi:10.1371/journal.pone.0022349

Peng, Y., Tomás, F.J.B., Klisch, C., Vida, I., Geiger, J.R.P., 2017. Layer-specific organization of local excitatory and inhibitory synaptic connectivity in the rat presubiculum. Cereb. Cortex 27, 2435-2452. doi:10.1093/cercor/bhx049

Penttonen, M., Kamondi, A., Acsády, L., Buzsáki, G., 1998. Gamma frequency oscillation in the hippocampus of the rat: intracellular analysis in vivo. Eur. J. Neurosci. 10, 718-728. doi:10.1046/j.1460-9568.1998.00096.x

Peyrache, A., Lacroix, M.M., Petersen, P.C., Buzsáki, G., 2015. Internally organized mechanisms of the head direction sense. Nat. Neurosci. 18, 569-575. doi:10.1038/nn.3968

Peyrache, A., Schieferstein, N., Buzsáki, G., 2017. Transformation of the head-direction signal into a spatial code. Nat. Commun. 8. doi:10.1038/s41467-017-01908-3

Potvin, O., Doré, F.Y., Goulet, S., 2009. Lesions of the dorsal subiculum and the dorsal hippocampus impaired pattern separation in a task using distinct and overlapping visual stimuli. Neurobiol. Learn. Mem. 91, 287-297. doi:10.1016/j.nlm.2008.10.003

Potvin, O., Doré, F.Y., Goulet, S., 2007. Contributions of the dorsal hippocampus and the dorsal subiculum to processing of idiothetic information and spatial memory. Neurobiol. Learn. Mem. 87, 669-678. doi:10.1016/j.nlm.2007.01.002

Potvin, O., Lemay, F., Dion, M., Corado, G., Doré, F.Y., Goulet, S., 2010. Contribution of the dorsal subiculum to memory for temporal order and novelty detection using objects, odors, or spatial locations in the rat. Neurobiol. Learn. Mem. 93, 330-336. doi:10.1016/j.nlm.2009.11.007

Roy, D.S., Kitamura, T., Okuyama, T., Ogawa, S.K., Sun, C., Obata, Y., Yoshiki, A., Tonegawa, S., 2017. Distinct neural circuits for the formation and retrieval of episodic memories. Cell 170, 1000-1012.e19. doi:10.1016/j.cell.2017.07.013

Royer, S., Sirota, A., Patel, J., Buzsáki, G., 2010. Distinct representations and theta dynamics in dorsal and ventral hippocampus. J. Neurosci. 30, 1777-1787. doi:10.1523/JNEUROSCI.4681-09.2010

Sahay, A., Scobie, K.N., Hill, A.S., O’Carroll, C.M., Kheirbek, M.A., Burghardt, N.S., Fenton, A.A., Dranovsky, A., Hen, R., 2011a. Increasing adult hippocampal neurogenesis is sufficient to improve pattern separation. Nature 472, 466-470. doi:10.1038/nature09817

Sahay, A., Wilson, D.A., Hen, R., 2011b. Pattern separation: a common function for new neurons in hippocampus and olfactory bulb. Neuron 70, 582-588. doi:10.1016/j.neuron.2011.05.012

Santarelli, L., Saxe, M., Gross, C.T., Surget, A., Battaglia, F., Dulawa, S., Weisstaub, N., Lee, J., Duman, R., Arancio, O., Belzung, C., Hen, R., 2003. Requirement of 
hippocampal neurogenesis for the behavioral effects of antidepressants. Science (80-. ). 301, 805-9. doi:10.1126/science.1083328

Sargolini, F., Fyhn, M., Hafting, T., McNaughton, B.L., Witter, M.P., Moser, M.B., Moser, E.I., 2006. Conjunctive representation of position, direction, and velocity in entorhinal cortex. Science (80-. ). 312, 758-762. doi:10.1126/science.1125572

Seress, L., Ábrahám, H., Lin, H., Totterdell, S., 2002. Nitric oxide-containing pyramidal neurons of the subiculum innervate the CA1 area. Exp. Brain Res. 147, 38-44. doi:10.1007/s00221-002-1242-2

Seress, L., Gulyás, A.I., Ferrer, I., Tunon, T., Soriano, E., Freund, T.F., 1993. Distribution, morphological features, and synaptic connections of parvalbuminand calbindin D28k-immunoreactive neurons in the human hippocampal formation. J. Comp. Neurol. 337, 208-230. doi:10.1002/cne.903370204

Shao, L.-R., Dudek, F.E., 2007. Electrophysiological evidence using focal flash photolysis of caged glutamate that CA1 pyramidal cells receive excitatory synaptic input from the subiculum. J. Neurophysiol. 3007-3011. doi:10.1152/jn.00877.2004

Sharp, P.E., 2006. Subicular place cells generate the same "map" for different environments: comparison with hippocampal cells. Behav. Brain Res. doi:10.1016/j.bbr.2006.05.034

Sharp, P.E., 1999. Comparison of the timing of hippocampal and subicular spatial signals: implications for path integration. Hippocampus 9, 158-172. doi:10.1002/(SICI)1098-1063(1999)9:2<158::AID-HIPO7>3.0.CO;2-O

Sharp, P.E., 1997. Subicular cells generate similar spatial firing patterns in two geometrically and visually distinctive environments: comparison with hippocampal place cells. Behav. Brain Res. 85, 71-92. doi:10.1016/S0166-4328(96)00165-9

Sharp, P.E., Green, C., 1994. Spatial correlates of firing patterns of single cells in the subiculum of the freely moving rat. J. Neurosci. 14, 2339-2356.

Sheppard, A.M., Brunstrom, J.E., Thornton, T.N., Gerfen, R.W., Broekelmann, T.J., McDonald, J.A., Pearlman, A.L., 1995. Neuronal production of fibronectin in the cerebral cortex during migration and layer formation is unique to specific cortical domains. Dev. Biol. 172, 504-518. doi:10.1006/dbio.1995.8034

Shibata, H., 1993. Direct projections from the anterior thalamic nuclei to the retrohippocampal region in the rat. J. Comp. Neurol. 337, 431-445. doi:10.1002/cne.903370307

Shor, O.L., Fidzinski, P., Behr, J., 2009. Muscarinic acetylcholine receptors and voltage-gated calcium channels contribute to bidirectional synaptic plasticity at CA1-subiculum synapses. Neurosci. Lett. 449, 220-223. doi:10.1016/j.neulet.2008.11.012

Simonnet, J., Eugène, E., Cohen, I., Miles, R., Fricker, D., 2013. Cellular neuroanatomy 
of rat presubiculum. Eur. J. Neurosci. 37, 583-597. doi:10.1111/ejn.12065

Simonnet, J., Nassar, M., Stella, F., Cohen, I., Mathon, B., Boccara, C.N., Miles, R., Fricker, D., 2017. Activity dependent feedback inhibition may maintain head direction signals in mouse presubiculum. Nat. Commun. 8, 16032. doi:10.1038/ncomms16032

Skaggs, W.E., McNaughton, B.L., 1996. Replay of neuronal firing sequences in rat hippocampus during sleep following spatial experience. Science (80-. ). 271, 1870-1873. doi:10.1126/science.271.5257.1870

Soriano, E., Martinez, A., Fariñas, I., Frotscher, M., 1993. Chandelier cells in the hippocampal formation of the rat: the entorhinal area and subicular complex. J. Comp. Neurol. 337, 151-167. doi:10.1002/cne.903370110

Souza, B.C., Tort, A.B.L., 2017. Asymmetry of the temporal code for space by hippocampal place cells. Sci. Rep. 7, 8507. doi:10.1038/s41598-017-08609-3

Staff, N.P., Jung, H.Y., Thiagarajan, T., Yao, M., Spruston, N., 2000. Resting and active properties of pyramidal neurons in subiculum and CA1 of rat hippocampus. J. Neurophysiol. 84, 2398-2408. doi:10.1016/0959-4388(93)90214-j

Stark, E., Roux, L., Eichler, R., Senzai, Y., Royer, S., Buzsáki, G., 2014. Pyramidal cell-interneuron interactions underlie hippocampal ripple oscillations. Neuron 83, 467-480. doi:10.1016/j.neuron.2014.06.023

Steward, O., Scoville, S.A., 1976. Cells of origin of entorhinal cortical afferents to the hippocampus and fascia dentata of the rat. J. Comp. Neurol. 169, 347-370. doi:10.1002/cne.901690306

Stewart, M., Wong, R.K., 1993. Intrinsic properties and evoked responses of guinea pig subicular neurons in vitro. J. Neurophysiol. 70, 232-45.

Strange, B.A., Witter, M.P., Lein, E.S., Moser, E.I., 2014. Functional organization of the hippocampal longitudinal axis. Nat. Rev. Neurosci. doi:10.1038/nrn3785

Sun, Y., Nguyen, A.Q., Nguyen, J.P., Le, L., Saur, D., Choi, J., Callaway, E.M., Xu, X., 2014. Cell-type-specific circuit connectivity of hippocampal CA1 revealed through cre-dependent rabies tracing. Cell Rep. 7, 269-280. doi:10.1016/j.celrep.2014.02.030

Swanson, L.W., Cowan, W.M., 1977. An autoradiographic study of the organization of the efferet connections of the hippocampal formation in the rat. J. Comp. Neurol. 172, 49-84. doi:10.1002/cne.901720104

Takahashi, S., 2015. Episodic-like memory trace in awake replay of hippocampal place cell activity sequences. Elife 4. doi:10.7554/eLife.08105

Tamamaki, N., Nojyo, Y., 1995. Preservation of topography in the connections between the subiculum, field CA1, and the entorhinal cortex in rats. J. Comp. Neurol. 353, 379-390. doi:10.1002/cne.903530306 
Tamamaki, N., Nojyo, Y., 1993. Projection of the entorhinal layer II neurons in the rat as revealed by intracellular pressure-injection of neurobiotin. Hippocampus 3, 471-480. doi:10.1002/hipo.450030408

Taube, J.S., 2007. The head direction signal: origins and sensory-motor integration. Annu. Rev. Neurosci. 30, 181-207. doi:10.1146/annurev.neuro.29.051605.112854

Taube, J.S., 1993. Electrophysiological properties of neurons in the rat subiculum in vitro. Exp Brain Res 96, 304-318.

Taube, J.S., Muller, R.U., Ranck, JB, Jr., 1990a. Head-direction cells recorded from the postsubiculum in freely moving rats. I. Description and quantitative analysis. J. Neurosci. 10, 420-35. doi:10.1212/01.wnl.0000299117.48935.2e

Taube, J.S., Muller, R.U., Ranck, JB, Jr., 1990b. Head-direction cells recorded from the postsubiculum in freely moving rats. II. Effects of environmental manipulations. J. Neurosci. 10, 436-447. doi:10.1212/01.wnl.0000299117.48935.2e

Tsanov, M., Chah, E., Vann, S.D., Reilly, R.B., Erichsen, J.T., Aggleton, J.P., O’Mara, S.M., 2011. Theta-modulated head direction cells in the rat anterior thalamus. J. Neurosci. 31, 9489-9502. doi:10.1523/JNEUROSCI.0353-11.2011

Tukker, J.J., Tang, Q., Burgalossi, A., Brecht, M., 2015. Head-directional tuning and theta modulation of anatomically identified neurons in the presubiculum. J. Neurosci. 35, 15391-15395. doi:10.1523/JNEUROSCI.0685-15.2015

van Strien, N.M., Cappaert, N.L.M., Witter, M.P., 2009. The anatomy of memory: an interactive overview of the parahippocampal-hippocampal network. Nat. Rev. Neurosci. 10, 272-282. doi:10.1038/nrn2614

Vazdarjanova, A., Guzowski, J.F., 2004. Differences in hippocampal neuronal population responses to modifications of an environmental context: evidence for distinct, yet complementary, functions of CA3 and CA1 ensembles. J. Neurosci. 24, 6489-6496. doi:10.1523/JNEUROSCI.0350-04.2004

Vogt, B.A., Miller, M.W., 1983. Cortical connections between rat cingulate cortex and visual, motor, and postsubicular cortices. J. Comp. Neurol. 216, 192-210. doi:10.1002/cne.902160207

Wang, W.T., Wan, Y.H., Zhu, J.L., Lei, G.S., Wang, Y.Y., Zhang, P., Hu, S.J., 2006. Theta-frequency membrane resonance and its ionic mechanisms in rat subicular pyramidal neurons. Neuroscience 140, 45-55. doi:10.1016/j.neuroscience.2006.01.033

Wang, Y., Xu, C., Xu, Z., Ji, C., Liang, J., Wang, Y., Chen, B., Wu, X., Gao, F., Wang, S., Guo, Y., Li, X., Luo, J., Duan, S., Chen, Z., 2017. Depolarized GABAergic signaling in subicular microcircuits mediates generalized seizure in temporal lobe epilepsy. Neuron 95, 92-105.e5. doi:10.1016/j.neuron.2017.08.013

Wellmer, J., Su, H., Beck, H., Yaari, Y., 2002. Long-lasting modification of intrinsic 
discharge properties in subicular neurons following status epilepticus. Eur. J. Neurosci. 16, 259-266. doi:10.1046/j.1460-9568.2002.02086.x

Wilson, M., McNaughton, B., 1994. Reactivation of hippocampal ensemble memories during sleep. Science (80-. ). 265, 676-679. doi:10.1126/science.8036517

Witter, M.P., 2006. Connections of the subiculum of the rat: topography in relation to columnar and laminar organization. Behav. Brain Res. 174, 251-264. doi:10.1016/j.bbr.2006.06.022

Witter, M.P., 1993. Organization of the entorhinal-hippocampal system: a review of current anatomical data. Hippocampus 3, 33-44. doi:10.1002/hipo.1993.4500030707

Witter, M.P., Ostendorf, R.H., Groenewegen, H.J., 1990. Heterogeneity in the dorsal subiculum of the rat. Distinct neuronal zones project to different cortical and subcortical targets. Eur. J. Neurosci. 2, 718-725. doi:10.1111/j.14609568.1990.tb00462.x

Wouterlood, F.G., Saldana, E., Witter, M.P., 1990. Projection from the nucleus reuniens thalami to the hippocampal region: light and electron microscopic tracing study in the rat with the anterograde tracer Phaseolus vulgaris-leucoagglutinin. J. Comp. Neurol. 296, 179-203. doi:10.1002/cne.902960202

Wozny, C., Knopp, A., Lehmann, T.-N., Heinemann, U., Behr, J., 2005. The subiculum: a potential site of ictogenesis in human temporal lobe epilepsy. Epilepsia 46 Suppl 5, 17-21. doi:10.1111/j.1528-1167.2005.01066.x

Wright, N.F., Erichsen, J.T., Vann, S.D., O’Mara, S.M., Aggleton, J.P., 2010. Parallel but separate inputs from limbic cortices to the mammillary bodies and anterior thalamic nuclei in the rat. J. Comp. Neurol. 518, 2334-2354. doi:10.1002/cne.22336

Wu, C.-T., Haggerty, D., Kemere, C., Ji, D., 2017. Hippocampal awake replay in fear memory retrieval. Nat. Neurosci. 20, 571-580. doi:10.1038/nn.4507

Wyss, J., 1981. An autoradiographic study of the efferent connections of the entorhinal cortex in the rat. J. Comp. Neurol. 199, 495-512. doi:10.1002/cne.901990405

Xu, X., Sun, Y., Holmes, T.C., López, A.J., 2016. Noncanonical connections between the subiculum and hippocampal CA1. J. Comp. Neurol. 524, 3666-3673. doi:10.1002/cne.24024

Yamamoto, J., Suh, J., Takeuchi, D., Tonegawa, S., 2014. Successful execution of working memory linked to synchronized high-frequency gamma oscillations. Cell 157, 845-857. doi:10.1016/j.cell.2014.04.009

Ylinen, A., Bragin, A., Nádasdy, Z., Jandó, G., Szabó, I., Sik, A., Buzsáki, G., 1995. Sharp wave-associated high-frequency oscillation $(200 \mathrm{~Hz})$ in the intact hippocampus: network and intracellular mechanisms. J. Neurosci. 15, 30-46. 
doi:10.1038/17605

Yoder, R.M., Clark, B.J., Taube, J.S., 2011. Origins of landmark encoding in the brain. Trends Neurosci. 34, 561-571. doi:10.1016/j.tins.2011.08.004

Zemankovics, R., Káli, S., Paulsen, O., Freund, T.F., Hájos, N., 2010. Differences in subthreshold resonance of hippocampal pyramidal cells and interneurons: the role of h-current and passive membrane characteristics. J. Physiol. 588, 2109-2132. doi:10.1113/jphysiol.2009.185975 


\section{Figure Legends}

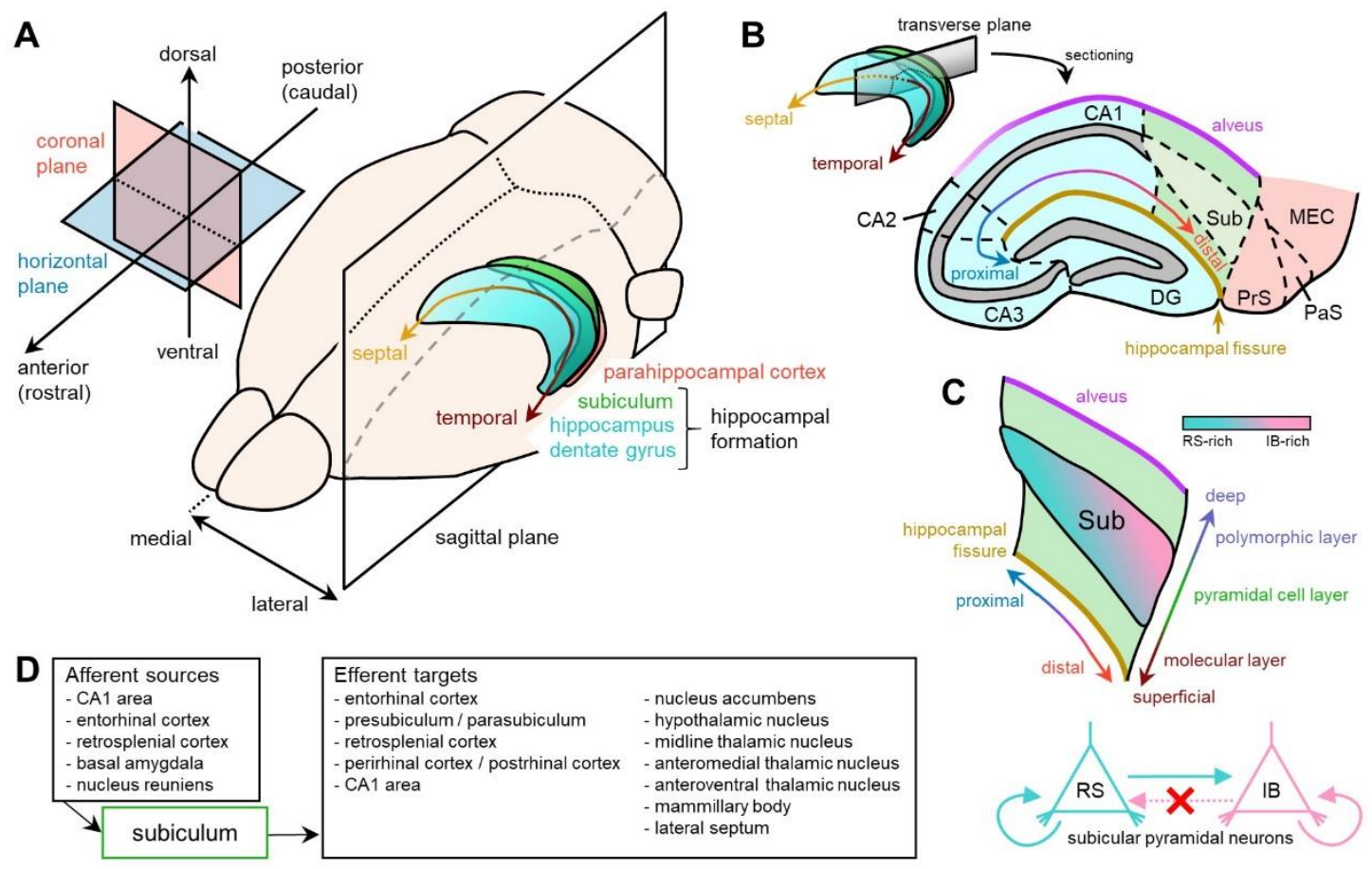

Figure 1. Anatomy of the rat subiculum. $A$, Diagonal view of the rat brain. The hippocampal formation (green and pale blue) and parahippocampal cortex (red) are inside the brain. The hippocampal formation includes the hippocampus (pale blue), dentate gyrus (pale blue), and subiculum (green). Three representative reference axes and corresponding cardinal planes are shown: the anteroposterior (rostrocaudal (in rat)), dorsoventral, and mediolateral axes are perpendicular to the coronal, horizontal, and sagittal planes, respectively. The hippocampal formation has a C-shaped curve; the end closer to the septum is referred to as the septal pole, whereas the end abutting on the temporal lobe is called the temporal pole. Note that the hippocampal dorsal and ventral horns correspond to the septal and temporal poles, respectively, in rodents (McNaughton, 2006; Strange et al., 2014). B, An example transverse section of the dorsal hippocampal formation and parahippocampal cortex. The hippocampus, dentate gyrus, subiculum, and parahippocampal cortex (such as presubiculum, parasubiculum, and medial entorhinal cortex) are shown. The hippocampus is further subdivided into the CA1, CA2, and CA3 subareas. In the hippocampus, the proximodistal axis is defined in accordance with the proximity of the dentate gyrus. The hippocampal fissure, or the hippocampal sulcus (gold), isolates the CA1 area and subiculum from the dentate gyrus. The alveus (purple) is composed of white myelinated axonal fibers of hippocampal and subicular pyramidal neurons. Note that the transverse plane is perpendicular to the septotemporal (longitudinal) axis shown as a yellow-to-brown line. $C$, The subiculum has a three-layered appearance including a polymorphic layer, pyramidal cell layer, and molecular layer. The 
molecular layer is closest to the hippocampal fissure. The subicular pyramidal cell layer is flanked by the molecular layer and the polymorphic layer. The polymorphic layer is nearer to the alveus. The superficial and deep layers are defined by their proximity to the hippocampal fissure and alveus, respectively. Within the subicular pyramidal cell layer, more regular-spiking neurons (pale blue) are located in a more superficial and proximal subfield, whereas more intrinsically bursting neurons (pink) are located in a deeper and more distal subfield. There is recurrent circuitry within regular-spiking and bursting neurons. Regular-spiking neurons make synapses with bursting neurons but not vice versa (Böhm et al., 2015). D, Interregional projections from and to the dorsal subiculum are shown. Abbreviations: Sub, subiculum; DG, dentate gyrus; PrS, presubiculum; PaS, parasubiculum; MEC, medial entorhinal cortex; RS, regular-spiking neurons; IB, intrinsically bursting neurons. 
A
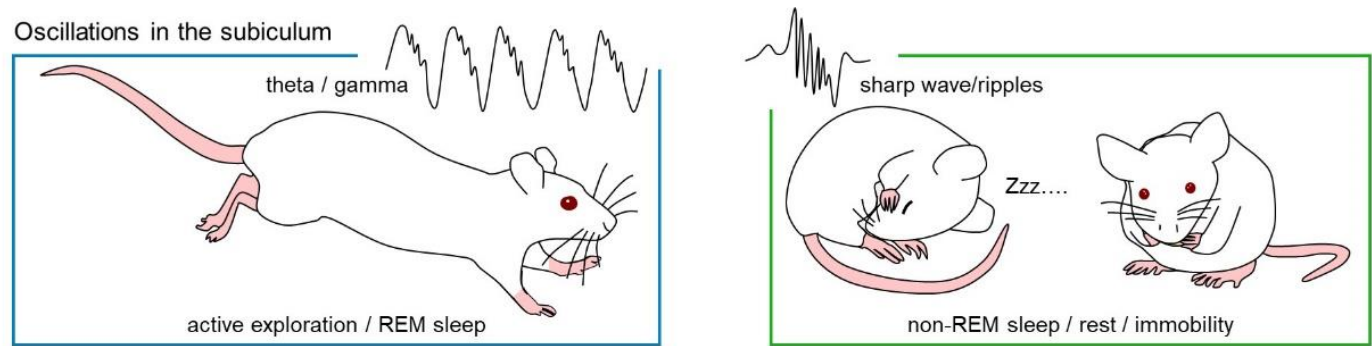

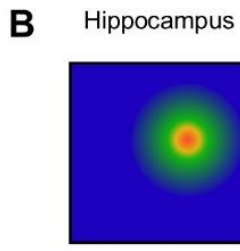

place cell
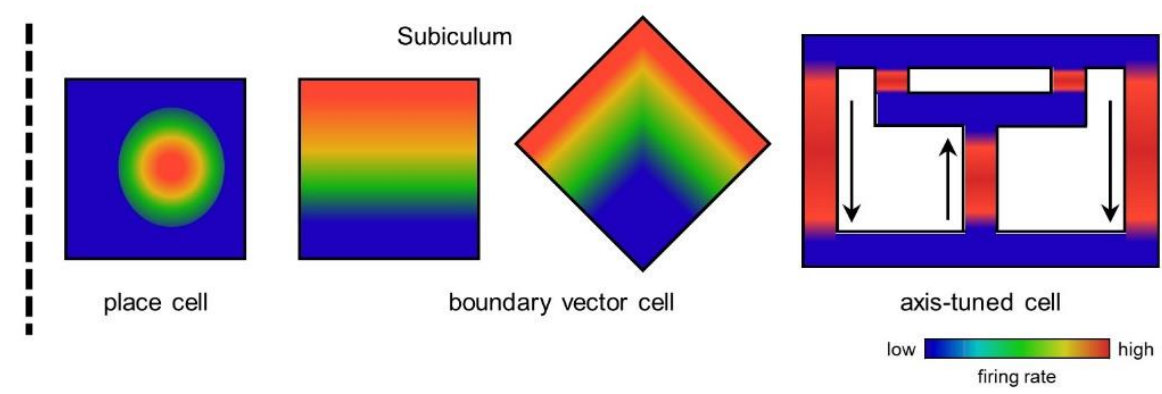

Figure 2. Physiology of the rat subiculum. $A$, Extracellular oscillations in the rodent subiculum. Theta and gamma oscillations are observed during active exploration and REM sleep, whereas sharp wave/ripple complexes are observed during non-REM sleep, rest, and immobility. $B$, Comparison of firing maps between hippocampal and subicular spatial cells. A hippocampal place cell in a square open arena (left-most panel), a subicular place cell (second panel), a subicular boundary vector cell (Lever et al., 2009) (third panel), a boundary vector cell in a different environment (Lever et al., 2009) (fourth panel), and a subicular axis-tuned cell (Olson et al., 2016) (fifth panel). The arrows in the fifth panel indicate the animal's direction of movement. Warm and cold colors indicate high and low firing rates, respectively. Abbreviations: REM, rapid eye movement. 